\title{
The Option Market's Anticipation of Information Content in Earnings Announcements
}

\author{
Mary Brooke Billings \\ New York University \\ mbilling@stern.nyu.edu \\ Robert Jennings \\ Indiana University \\ jennings@indiana.edu
}

April 2010

\begin{abstract}
We develop an ex ante measure of the information content of earnings announcements that allows us to estimate the stock market's response to news in upcoming earnings releases. Exploiting a powerful setting in the option market, our measure of anticipated information content (the AIC) separates the magnitude of the stock market's reaction to earnings information from earnings uncertainty. Our results suggest that option traders rationally anticipate the sensitivity of stock prices to earnings information and they do so in a way that recognizes crosssectional and time-series differences in the strength of the link between returns and earnings. Specifically, we find the AIC positively correlates with the magnitude of the ex post stock market sensitivity to unexpected earnings. In further tests, we document that the AIC increases with earnings persistence, firm growth prospects, the richness of firms' information environments and the presence of sophisticated ownership structures and decreases with anticipated discount rates. This paper sheds light on whether and how information content manifests in the option market and, in so doing, it introduces several opportunities for future study.

Keywords: information content of earnings announcements; options; volatility; institutional ownership; information environment; return-earnings relation; earnings response coefficients JEL Classification: M41; M49; G14; G29

This paper benefited from the insightful comments of Eli Bartov, Daniel Beneish, Brian Cadman, Gavin Cassar, Melissa Lewis, Alexander Nezlobin, Jim Ohlson, Steve Ryan, Jerry Salamon, Wayne Thomas, Andrey Ukhov, Jim Wahlen, workshop participants at Indiana University and the University of Utah, and participants at the 2009 New York University Summer Camp and the 2010 Columbia-NYU Workshop. We thank Brian Bushee for supplying institutional ownership classification coding.
\end{abstract}




\section{Introduction}

In this paper, we argue that the listed equity options market rationally anticipates the information content of upcoming earnings releases. Because option values closely relate to the market's estimate of the stock return volatility over the option's life, option traders must consider the potential effect that predictable news events have on this volatility. We use this relation between current option prices and future news-induced stock price volatility to extract a forecast of the information content of earnings announcements. In so doing, we isolate the market's anticipation of the magnitude of the stock market's reaction to earnings information from its uncertainty about the level of earnings and show that this predicted sensitivity allows for crosssectional and time-series differences in the link between returns and earnings.

Absent a volatility-increasing event, options with little time to expiration and with an exercise price approximately equal to their underlying stock price should be virtually worthless (Black and Scholes, 1973). Yet, empirical evidence suggests that short-dated, at-the-money options expiring soon after an anticipated earnings announcement date typically trade for nontrivial market values (Patell and Wolfson, 1979, 1981). In fact, prior work studying the behavior of option prices typically excludes short-dated options from analysis precisely because of these noted "erratic" spikes in value (Schmalensee and Trippi, 1978; Patell and Wolfson, 1979, 1981; Manaster and Rendleman, Jr., 1982). We, however, view these options as exceptionally interesting with respect to their ability to supply a measure of traders' allowance for upcoming information content. In particular, we hypothesize that these options derive their market value from traders' forecasting sharp, earnings-induced increases in stock price volatility. In other words, we predict that soon-to-expire, at-the-money options become valuable when traders believe that an upcoming earnings announcement will elicit a stock market reaction. Indeed, we 
expect that because option prices reflect forward-looking estimates of the underlying stock price volatility through the option's expiration date (referred to as the implied volatility), they will increase or decrease depending upon traders' expectations regarding the strength of the link between stock market behavior and the release of earnings. Consequently, we use the fact that short-dated, at-the-money options would trade for very little absent an upcoming earnings release to supply us with a powerful setting to study the extent to which anticipated earnings information influences behavior in the option market. ${ }^{1}$

Earnings announcements increase stock price volatility (Beaver, 1968) and this is reflected in the option's implied volatility (Patell and Wolfson, 1979, 1981). The magnitude of this earnings-induced increase in implied volatility depends on (1) the uncertainty of earnings information and (2) the magnitude of the market's response to the earnings information. Relying upon this insight, we develop a volatility-driven measure of information content that separates the effect of earnings uncertainty from the stock price's sensitivity to earnings information. Specifically, we isolate the option market's anticipation of information content (AIC) by deflating the price of an equity option expiring soon after an impending earnings announcement by an ex ante measure of earnings uncertainty, the standard deviation of analysts' forecasts (Imhoff and Lobo, 1992; Barron et al., 1998). In so doing, we obtain a ratio, the AIC, that reflects the fact that for any given level of earnings uncertainty, the option price should increase with the forecasted elasticity of the stock market's response to earnings information.

\footnotetext{
${ }^{1}$ For example, consider an option with a $\$ 50$ strike price that expires in two days. If the firm's stock currently trades for $\$ 50$ and its normal annual volatility is 25 percent $(1.58 \%$ per day, assuming identically and independently distributed returns across the approximately 250 trading days per year), then the theoretical option value (derived using Black and Scholes, 1973) equals 36 or 37 cents using a 4\% annual risk-free interest rate. Suppose that the market anticipates that an earnings release will occur the day before the option expires and that the market believes that the impending announcement will cause a three-sigma movement in the stock price. If investors consider the influence of this impending earnings news on the firm's stock price, the market prices the option to incorporate the three-sigma stock price movement. Consequently, in this case, the option sells for around $\$ 2.37$ (= $\$ 50 * 0.0158 * 3$ ), which reflects an implied volatility of approximately $160 \%$.
} 
We use data from OptionMetrics and I/B/E/S to calculate 39,443 unique AICs for 18,214 unique firm quarters from 1996 through 2006. In our sample selection process, we aim to increase the power of our tests by restricting our analysis to the observations for which we expect the impending earnings news to most significantly affect the price of the option. Accordingly, we focus on the prices of short-dated, at-the-money options expiring soon after an expected earnings announcement. We then use the AIC to examine how information content manifests in the option market. In so doing, we provide evidence that option traders anticipate the informativeness of earnings releases and do so in a way that allows for cross-sectional and timeseries differences in the strength of the link between returns and earnings. In particular, initial tests indicate that our ex ante information content metric (the AIC) positively correlates with the magnitude of the ex post stock market reaction to unexpected earnings. Subsequent tests document that the AIC increases with earnings persistence, firm growth prospects, the richness of firms' information environments and the presence of sophisticated ownership structures (i.e., transient institutional investors known to trade aggressively based on earnings information) and decreases with anticipated discount rates (i.e., firm risk and interest rate levels).

This paper studies the information content of earnings reports by shifting attention from how earnings news influences stock prices to considering the role that earnings information plays in shaping option-market behavior. Recent empirical work indicates that option traders anticipate a stock-market reaction to firms' earnings disclosures (Amin and Lee, 1997; Ni et al., 2008; Xing et al., 2009). We use a powerful setting in the option market to develop an approach to studying information content that isolates the volatility-induced spike in option price that stems from traders' expectations of a stock market response to the release of earnings. Accordingly, we build on recent work by supplying evidence that is consistent with option 
traders playing an important role in the price discovery process via their anticipation of the magnitude of the stock market's response to the release of earnings. Indeed, we identify several cross-sectional and inter-temporal determinants of the option market's anticipation of information content in earnings releases. As a result, we connect the recent stream of literature examining trading behavior in the option market to the fundamental stream of accounting literature examining the information content of earnings. Consequently, this paper sheds light on whether and how information content manifests in the option market and, in so doing, it offers researchers a continuously available, ex ante, firm- and quarter-specific approach to studying the totality of information associated with earnings announcements that introduces many opportunities for future research.

The AIC allows researchers to study firm-specific events that might influence the informativeness of firms' earnings without waiting until the next earnings announcement. Because the AIC captures the market's current information regarding the likely stock-price impact of a specific upcoming earnings announcement in a frequently measurable, firm- and quarter-specific fashion, researchers can conduct event studies that more precisely examine the changes in (as opposed to levels of) the market's sensitivity to earnings information. At the same time, the ex ante nature of the AIC affords researchers the opportunity to investigate the degree to which the market anticipates as opposed to reacts to the event of interest. Further, in contrast to a focus on the impact of current period earnings, the AIC captures forecasted volatility associated with the entirety of information accompanying an earnings release. Consequently, our approach to studying earnings informativeness would allow researchers to assess the role that supplemental disclosures (e.g., conference call discussions) play in affecting market participants' beliefs about the strength of the link between stock market behavior and 
earnings information. As discussed later in the paper, several additional research possibilities stem from studying information content from the perspective of the options market.

The remainder of this paper progresses as follows. Section 2 discusses related literature. Section 3 describes our sample selection process and relates our research design. Following that, we present our results in Section 4. Finally, Section 5 concludes with a summary of our findings as well as a discussion of future research.

\section{Related literature}

An extensive accounting literature takes various approaches to assessing the link between stock market behavior and the release of earnings (Ball and Brown, 1968; Beaver, 1968; May, 1971; Chambers and Penman, 1984; Amin and Lee, 1997; Ni et al, 2008; Xing et al., 2009). Our paper combines insights from: (1) work documenting the information content of accounting earnings and (2) studies of option markets around earnings announcements. The stream of literature examining the stock market reaction to earnings begins with the seminal work of Beaver (1968) and Ball and Brown (1968). The majority of subsequent work focuses on the relation between earnings news and stock returns. Early studies document a positive correlation between magnitudes of earnings innovations and stock returns (e.g., Beaver, Clarke, and Wright, 1979; Beaver, Lambert, and Morse, 1980), suggesting that good earnings news results in a positive revaluation of the firm's equity. Building upon this early work, researchers frequently test the information content of accounting earnings by regressing earnings innovations on contemporaneous stock returns (or estimating a reverse regression of these variables). The slope coefficients from these regressions are known as earnings response coefficients (ERCs). Given evidence of a return-earnings relation, later studies (e.g., Kormendi and Lipe, 1987; Collins and Kothari, 1989; Easton and Zmijewski, 1989; summarized in Kothari 2001) document cross- 
sectional and time-series differences in ERCs. In particular, these studies supply evidence of a positive relation between ERCs and both earnings persistence and economic growth opportunities and evidence of a negative relation between ERCs and anticipated discount rates (i.e., firm risk and interest rate levels).

The intuition behind our option-market approach to examining earnings informativeness begins by observing that option traders play an important role in the price discovery process (Cremers and Weinbaum, 2010). Because option prices reflect forward-looking estimates of the underlying stock price volatility through the option's expiration date, traders should rationally anticipate the impact of impending news, including sharp increases in stock price volatility around earnings releases. Indeed, Patell and Wolfson $(1979,1981)$ find that implied volatilities increase dramatically as an earning dates approach and collapse thereafter. They also find that the volatilities forecasted by the option market are, on average, realized. Consistent with this notion, recent work documents that option-market traders appear to anticipate upcoming earnings releases. Should traders believe that they can forecast the direction of stock price changes associated with future earnings releases (see Amin and Lee, 1997), the current stock price will reflect these favorable/unfavorable beliefs. To the extent that option traders are uncertain about direction (i.e., they cannot assign an expected sign to the upcoming information), but anticipate an increase in stock price volatility around the earnings announcement, option prices should incorporate this expected variance (e.g., Ni et al, 2008; Xing et al., 2009).

Although we believe that option traders consider the ex post sensitivity of stock prices to earnings news and document that is indeed the case, we expect our volatility-driven information content metric to behave distinctly from the traditional earnings-return relation, as measured by the ERC. First, in contrast to the ERC's focus on the impact of current period earnings, the AIC 
responds to forecasted volatility associated with the entire earnings announcement. ${ }^{2}$ Second, the firm- and quarter-specific nature of the AIC metric (as well as the inputs used in the calculation) differs fundamentally from the traditional, regression approach to estimating an ERC. Third, and more broadly, our option-market focus, along with our use of analyst forecast data, cause us to study a sample of firms that experience substantial trading interest and stock price volatility such that they attract the attention of option exchanges and financial analysts. This suggests that our sample firms operate in particularly rich information environments characterized by large amounts of pre-disclosure information. Finally, although we hypothesize that option prices anticipate stock market movements (and, therefore, might exhibit ERC-like behavior), volatility drives option prices, which suggests that the AIC might also exhibit behavior similar to that documented in volatility-based studies of information content (e.g., Atiase, 1985). Taken collectively, these methodological differences: 1) eliminate our ability to compare the scale/magnitude of the AIC to other measures, 2) cause us to expect only a modest correlation between the AIC and the ERC, and 3) lead us to believe that our sample firms' information environments might differ substantively from prior samples. These differences allow us to study the link between earnings and market behavior from a new perspective.

In summary, the study of the link between earnings information and stock market behavior addresses a fundamental question in the accounting literature. At the same time, research examining trading behavior in the option market surrounding earnings releases suggests that option prices reflect traders' anticipation of earnings-induced volatility. In the next section, we combine insights from these two established literatures to develop a measure of anticipated

\footnotetext{
${ }^{2}$ Indeed, earnings announcements can include additional information (above and beyond information about the firms' current earnings). Yet, for this additional information to influence the AIC, it must be 1) information that option traders can anticipate (i.e., option traders can forecast both content and timing of delivery), 2) information for which an impact on stock prices is expected, (i.e., value-relevant) and 3) information to which option traders cannot assign a valence (as an anticipated sign to the news would cause the underlying stock price to move instead). Given these requirements, we expect that the additional information captured by the AIC that is not captured by traditional ERCs largely pertains to future earnings streams.
} 
information content that exploits data in option prices prior to firm's earnings releases. Although we expect this measure to differ from traditional earnings informativeness measures in meaningful ways, we use prior work that examines the information content of earnings (with a particular emphasis on those studies that focus on the return-earnings relation) to guide us in forming our predictions about our measure's cross-sectional and inter-temporal variation.

\section{Sample selection and research design}

We define the option market's anticipation of information content (AIC) as the price of an equity option expiring soon after an impending earnings announcement normalized by the standard deviation of analysts' earnings forecasts for the quarter. The choice of numerator reflects the fact that option prices should consider (and, therefore, incorporate) the stock price volatility that investors expect to accompany earnings news. We deflate the option price by the standard deviation of analysts' forecasts - our ex ante measure of earnings uncertainty (Imhoff and Lobo, 1992; Barron et al., 1998). As a result, we obtain a ratio that reflects the fact that for a given level of earnings uncertainty, the option price should increase with the forecasted elasticity of the stock market's response to unexpected earnings-announcement news. Furthermore, because the AIC captures investors' anticipation of the link between earnings information and returns, we expect the AIC will differ both across firms and over time depending upon the expected strength of the return-earnings relation. ${ }^{3}$

\footnotetext{
${ }^{3}$ We can formalize the relation between option prices and the anticipated impact of earnings announcements on stock prices in a highly stylized world. Absent earnings news, assume that information is continuously impounded into stock prices so that stock price is a Brownian motion without drift. Earnings announcements, however, represent a discrete news event that potentially causes a "jump" in stock price. In our stylized world, this "jump" equals the magnitude of the earnings news multiplied by a non-negative coefficient representing the valuation relevance per unit of earnings news (e.g., if X represents earnings news, then $\mathrm{bX}$ represents the stock price change given a particular earnings surprise). To simplify matters, think of earnings news as a zeromean, normally distributed, random variable. The expected payoff to a very short-dated, at-the-money option without an earnings announcement is zero. If there is an earnings announcement during the option's life, then the expected payoff to a call option is the valuation-relevance-of-earnings coefficient multiplied by the expected value of the earnings news, conditional on the surprise being positive (e.g., $E[$ call payoff $]=b * E[X \mid X>0]$ ). The expected payoff to a put is analogously defined. Given our assumption about earnings news, its conditional expected value is a numerical constant multiplied by its standard deviation (e.g., $\mathrm{E}[\mathrm{X} \mid \mathrm{X}>0]=\mathrm{a}^{*}$ sigma). This implies that the expected payoff to an option is a numerical constant multiplied by the valuationrelevance-of-earnings coefficient times the uncertainly of earnings (e.g. E[payoff] $=a^{*} b^{*} \sigma$ ). Our measure of information content
} 
In order to calculate AICs, we require option pricing data and analyst forecast data. We obtain daily closing option prices and implied volatilities along with the option characteristics (strike prices, expiration dates, and put-call indicators) for individual equity options and these options' underlying-stock closing prices from Ivy DB OptionMetrics. Our sample period starts in January 1996 (the beginning of OptionMetrics) and ends with December 2006. We limit our analysis to options nearing expiration by collecting data for all traded options on individual common stocks starting four weeks (typically 20 trading days) before the option expiration date (EX_DATE). As discussed previously, Patell and Wolfson $(1979,1981)$ document that implied volatility spikes around earnings releases. ${ }^{4}$ Because they focus their analysis on the typical behavior of option prices between earnings releases, Patell and Wolfson exclude short-dated options (i.e., those within 20 days of expiration) from their sample. In our study, we view these options as particularly interesting, as we wish to permit the option market the best opportunity to fully anticipate the information content of the upcoming earnings announcement. Because the market is likely better able to forecast near-term events than those events farther away in time and because we wish to reduce the effect of other information events, we focus our attention to these short-dated options expiring soon after an expected earnings announcement. ${ }^{5}$

We obtain analyst forecast data from the summary files of $\mathrm{I} / \mathrm{B} / \mathrm{E} / \mathrm{S}$ International, Inc. The initial sample of data retrieved from $\mathrm{I} / \mathrm{B} / \mathrm{E} / \mathrm{S}$ focuses on forecasts of current-quarter primary earnings per share (EPS) for U.S. firms covered by at least two analysts. The restriction on the number of analysts allows us to have both a mean estimate (MEANEST) and a standard

for a given firm-quarter (expected option payoff divided by earnings uncertainty) is a numerical constant multiplied by the valuation-relevance-of-earnings coefficient (e.g., E[payoff] $/ \sigma=\mathrm{a}^{*} \mathrm{~b}$ ). Thus, cross-sectional and time-series influences on the coefficient tying earnings news to ex-earnings-announcement stock price movements also affect our information content metric.

${ }^{4}$ Rogers, Skinner and Van Buskirk (2009) also document an association between management forecasts and implied volatility.

${ }^{5}$ Unless we have reason to anticipate asymmetric stock price responses for positive or negative earnings surprises (perhaps because of accounting policies), the potential earnings information equally affects put and call options. 
deviation of analysts' forecasts (STDEV). We remove observations with missing actual reported values (ACTUAL) or missing report dates of actual earnings values (EA_DATE). ${ }^{6}$

We merge the OptionMetrics and $\mathrm{I} / \mathrm{B} / \mathrm{E} / \mathrm{S}$ data to obtain an initial sample of firm-quarters with available option and analyst forecast data. As indicated in Figure 1, when merging the two datasets, we require that an EA_DATE falls within the four weeks of option data. Thus, all retained merged data contain a series of option and stock prices that covers the period of time surrounding an EA_DATE. ${ }^{7}$ As described in Panel A of Table 1, this process supplies us with approximately 12.7 million total observations associated with 651,811 unique options and 4,363 unique firms. During the eleven-year sample period, we have 55,936 unique firm-quarters with data. In classifying our observations by year, we use the fiscal period ending date on I/B/E/S. As the EA_DATE typically follows the end of the fiscal period by several days or weeks, some data classified in a given year actually comes from the following calendar year.

The next step in our sample selection process aims to increase the power of our tests by restricting the sample to observations for which we expect the impending earnings news to most significantly affect the option's price (OPTPRICE). To do this, we compute the option's "moneyness" (M) by comparing the option's strike price (STRIKE) to the underlying stock's closing price (PRICE). Specifically, we calculate M for call (put) options as PRICE (STRIKE) divided by STRIKE (PRICE). We then limit our analysis to at-the-money options by focusing

\footnotetext{
${ }^{6}$ Conclusions do not change if we use the unadjusted (for stock splits) analyst forecasts in place of the adjusted forecasts (Payne and Thomas, 2003).

${ }^{7}$ Chambers and Penman (1984) provide evidence that earnings announcement dates vary little from year to year. Similarly, Bagnoli, Kross, and Watts (2002) provide evidence that the vast majority of earnings announcements occur on the date expected. Accordingly, assuming that the EA_DATE is known (one day before) is not unreasonable. Because of the firm-specific nature of earnings announcements, the length of the series of data leading up to and following the EA_DATE varies. If the EX_DATE falls on the EA_DATE, the series of data ends when the option expires and we remove the observation from the sample. In other words, we do not include any options that expire on or before the EA_DATE. Conclusions are unchanged if we limit our sample to observations having 17 (the median) or fewer calendar days between the EX_DATE and the EA_DATE.
} 
on observations where $\mathrm{M}$ falls between 0.95 and $1.05 .^{8}$ Finally, OptionMetrics does not compute the implied volatility (IVOL) for options with non-standard settlement arrangements. Because non-standard settlement may affect the option price in ways that add noise to our calculations, we remove observations with missing implied volatility measures. In Panel B of Table 1, we report that these restrictions reduce our final "AIC sample" to 39,443 options on 3,327 unique firms. Over our eleven years of data, we now have 18,214 unique firm-quarters.

We compute AIC by dividing the option price by the contemporaneous standard deviation of analysts' forecasts. That is,

$$
A I C_{t, i, j}=\frac{O P T P R I C E_{t, i, j}}{\operatorname{STDEV} V_{t, i}}
$$

where:

$\begin{array}{ll}t & =\text { day }-2 \text { or }-1 \text { in relation to the } E A_{-} D A T E ; \\ i & =\text { the index of individual firms; } \\ j & =\text { the index of individual options; } \\ \text { OPTPRICE }_{t, i, j} & =\text { the price of option } j \text { of firm } i \text { on time } t \text {; and } \\ \operatorname{STDEV}_{t, i} & =\text { the standard deviation of analysts' forecasts of firm } i \text { on time } t .\end{array}$

Because some options have missing data, we attempt to compute AICs both one and two days prior to the earnings release date. If we can compute an AIC on day -1 for a given option-firmquarter, we do not also use the day -2 statistic in our analyses. If the day -2 AIC exists when we do not have a day -1 AIC, then we use the day -2 statistic. $^{9}$

In calculating the AICs, we anticipate that the market considers the likely influence of the impending earnings news on the firm's stock price and, as a result, prices the option to

\footnotetext{
${ }^{8}$ Short-dated, at-the-money options are virtually worthless without the earnings-induced volatility spike. Because the potential movement in stock price associated with the impending earnings news is less likely to affect an out-of-the-money option, we remove options where $\mathrm{M}<0.95$. Although the anticipated stock price movement affects all in-the-money options (i.e., all options with $\mathrm{M}$ above 1), we remove options where $\mathrm{M}>1.05$, as this allows us to focus on observations for which the relative impact of the earnings news on OPTPRICE is likely the largest. In other words, we focus on observations for which the vega of the option (i.e., the option price's sensitivity to changes in implied volatility) is largest.

${ }^{9}$ Nearly all of the 39,443 AICs are day -1 as opposed to day -2 calculations (in relation to the EA_DATE). Indeed, 39,343 of the 39,443 AICs are day -1 calculations. Of the 100 calculations that relate to day -2 , the vast majority comes from the early years of OptionMetrics coverage (e.g., 71 of the 100 are from 1996).
} 
incorporate the possibility of a movement in stock price. Thus, a short-lived, at-the-money option might have a very low theoretical price using normal stock price volatility (i.e., volatility in a period of time without an earnings announcement). Yet, the implied volatility should elevate considerably for short-dated options with anticipated earnings announcements in the life of the option (our AIC sample of options). As noted by Patell and Wolfson (1981, Figure 5), the shortness of the option's life greatly exaggerates the implied annualized volatility. Because the standard deviation of analysts' forecasts increases with uncertainty about firms' earnings and has a positive correlation with ex post absolute earnings surprise (Barron et al., 1998; Burgstahler et al., 2002), we normalize the option price by STDEV. This allows us to obtain a ratio that reflects the fact that for any given level of earnings volatility, the option price should increase with the elasticity of the market's response.

Confirming the existence of a relation between our ex ante measure of earnings volatility and an ex post measure of earnings surprise in our sample, we detect a statistically significant (beyond the 0.0001 level) correlation of 0.54 between STDEV and the absolute value of SURPRISE (measured as the difference between ACTUAL and MEANEST). Figure 2, Panel A illustrates this point by sorting our data into deciles based on SURPRISE and plotting the average SURPRISE and average STDEV for these 10 groups. Consistent with Kinney, Burgstahler and Martin (2002, Figure 3), we observe a linear pattern between STDEV and the absolute value of SURPRISE.

As we argue that option traders should anticipate the stock price response to an earnings release, we first investigate the degree of association between the AIC and two more traditional measures of the earnings-return relation. Because the AIC is a firm- and quarter-specific measure of the information content of earnings announcements, we cannot compare it directly 
with the traditional ERC from a pooled cross-sectional regression. Instead, we investigate the correlation between our metric and (1) a firm-specific ERC and (2) a firm- and quarter-specific ratio of the price change on the earnings announcement date deflated by SURPRISE. First, we estimate the firm-specific ERC following Teets and Wasley (1996). Specifically, we calculate a firm-specific ERC that we obtain from estimating the slope coefficient from a simple ordinary least squares regression of earnings surprises (relative to mean $\mathrm{I} / \mathrm{B} / \mathrm{E} / \mathrm{S}$ forecast) normalized by stock price on announcement-day stock returns using the prior 20 quarters of data (with a minimum of 5 data points). ${ }^{10}$ Second, for the firm- and quarter-specific measure of price change per unit of earnings surprise, we divide the change in a stocks' price from close the day prior to the earnings announcement to close on the day earnings are released by SUPRISE.

Our next analyses investigate whether the AIC (an ex ante measure of informativeness) exhibits associations similar to those documented in the traditional information-content literature. Our initial tests address the question of whether we observe a nonlinear relation between the AIC and our earnings surprise proxy (STDEV), as suggested by the nonlinear relation between ERCs and earnings surprise observed by Freeman and Tse (1992). Then, because we hypothesize that the AIC should incorporate the ex post stock price reaction to an earnings release, we focus on determining whether AICs exhibit cross-sectional and time-series differences similar to those documented in extant work documenting the earnings-return relation.

Following prior research that examines the economic determinants of the earnings-return relation, we investigate the relation between AICs and fundamental economic and firm characteristics by estimating a regression based on the following model:

\footnotetext{
${ }^{10}$ Consistent with our concerns regarding the comparability of a firm- and quarter-specific measure and a coefficient estimate obtained via a pooled regression, Teets and Wasley (1996) note that firm-specific ERC estimates assume the firm's ERC remains constant across 20 quarters. As a result, they find that firm-specific ERCs, on average, differ substantially from those obtained from regressions that pool observations across both firms and time.
} 


$$
A I C_{t, i, j}=\gamma_{0}+\gamma_{1} M B_{t, i}+\gamma_{2} \beta_{t, i}+\gamma_{3} I_{t}+\gamma_{4} \theta_{i}+\gamma_{5} N U M_{t, i}+\varepsilon_{t},
$$

where:

$$
\begin{array}{rlrl}
t & = & \text { the time period index (now in relation to the firm quarter); } \\
i & = & \text { the index of individual firms; } \\
j & = & \text { the index of individual options; } \\
& \text { the end-of-prior-quarter ratio of market capitalization (Compustat Data } \\
M B_{t, i} & = & \text { Item No. } 14 * \text { Compustat Data Item No. } 61) \text { to book value of equity } \\
& \text { (Compustat Data Item No. 60); } \\
\beta_{t, i} & = & \text { systematic risk; } \\
I_{t} & = & \text { the end-of-prior-month U.S. Treasury 10-year interest rate; } \\
\theta_{i} & = & \text { a measure of earnings persistence; } \\
N U M_{t, i}= & \text { the number of analysts providing quarterly earnings forecasts on } \mathrm{I} / \mathrm{B} / \mathrm{E} / \mathrm{S} \\
& \text { when earnings are reported; and }
\end{array}
$$

As summarized by Kothari (2001), past work examining the return-earnings relation identifies growth, systematic risk, interest rates, and persistence as the four main determinants of ERCs (Kormendi and Lipe, 1987; Collins and Kothari, 1989; and Easton and Zmijewski, 1989). Accordingly, we include measures of each construct in Equation 2 and use these studies to guide us in forming our predictions about the signs of the coefficients. As in Collins and Kothari (1989), we include a measure of the firm's growth opportunities (MB) with the expectation that if current earnings provide information about the firm's growth prospects, the price response will be greater (i.e., $\left.\gamma_{1}>0\right) .{ }^{11}$ Relying on prior work that argues that greater non-diversifiable risk reduces the present value of the earnings innovations (Collins and Kothari, 1989; Easton and Zmijewski, 1989), we include $\beta$ (measured as the beta value provided in the CRSP file from the previous calendar year) and predict a negative coefficient (i.e., $\gamma_{2}<0$ ). Following a similar "discount-rate" rationale and consistent with Collins and Kothari (1989), we also include the risk-free rate of interest (I) and expect to observe a negative temporal relation (i.e., $\gamma_{3}<0$ ). Consistent with the notion that more persistent earnings lead to larger price changes as shown in

\footnotetext{
${ }^{11}$ Because of the skewed distribution of this variable (particularly during our sample period), we include the natural log of $M B$ in our regressions.
} 
Kormendi and Lipe (1987) and Easton and Zmijewski (1989), we include a measure of persistence $(\theta)$ and expect to observe a positive coefficient (i.e., $\gamma_{4}>0$ ). As in Beaver, Lambert and Morse (1980) and Collins and Kothari (1989), $\theta$ equals one minus the estimated first-order moving average coefficient in a time series model. ${ }^{12}$

The inclusion of a proxy for the richness of firms' information environments (NUM) allows us to investigate whether/how the availability of predisclosure information affects the option market's sensitivity to earnings information. Prior work indicates that firms' information environments affect the market's sensitivity to earnings information, perhaps via a "preemption" effect that increases the likelihood that prices lead earnings. Indeed, Atiase (1985) supplies evidence of an inverse relation between stock price volatility surrounding earnings announcements and firm size, suggesting that the increased availability of pre-disclosure information dampens the market response. ${ }^{13}$ Consistent with this idea, Kothari and Sloan (1992) note that ERCs computed using short-window returns around earnings announcements might be biased downward because of the stock market's ability to impute earnings news from sources of information that are more timely than earnings. Although our metric is a volatility-sensitive measure of information content, our sample firms' information environments likely differ considerably less than those in prior studies (i.e., even our smallest firm enjoys active trade and an analyst following suggesting a rich informational environment). Thus, because volatility drives the AIC (which suggests a negative relation) and, at the same time, our sample firms are

\footnotetext{
${ }^{12}$ Consistent with Collins and Kothari (1989), we estimate a single measure of earnings persistence using annual earnings over our sample period. Using a rolling, 20-quarter measure of persistence suggested by Easton and Zmijewski (1989) produces similar results.

${ }^{13}$ As his analysis requires only financial statement and stock return data, the difference between Atiase (1985)'s large and small firms differ substantially (i.e., his large firms are at least 20 times larger than his small firms).
} 
much more homogeneous in their information environments than are Atiase (1985), we make no prediction as to the expected sign of $\gamma_{5}{ }^{14}$

Before estimating Equation 2, we must recognize that our sample period (dictated by the availability of OptionMetrics) includes what has become known as the Internet "Bubble" period. During this period, accounting research (e.g., Trueman, Wong, and Zhang, 2000; Demers and Lev, 2001; Hand, 2001; Trueman, Wong, and Zhang, 2003; and Xu, Magnan, and Andre, 2007) demonstrates that traditional valuation metrics weaken and/or non-traditional valuation metrics become useful. This consideration is particularly important given our research design, as option exchanges tend to list options on stocks with high price volatility (see Mayhew and Mihov, 2004) - a feature that Internet stocks likely exhibit. Consequently, we adjust our research design in order to take into account the uniqueness of our sample period by revising our regression equation to include the following terms:

$$
\begin{aligned}
\operatorname{IERC}_{t, i, j}= & \gamma_{0}+\gamma_{1} D_{P B B}+\sum_{y=1997}^{y=2006} \gamma_{y} D_{y}+\gamma_{2} M B_{t, i}+\gamma_{3} M B_{t, i} * D_{P B B}+\gamma_{4} \beta_{t, i}+\gamma_{5} \beta_{t, i} * D_{P B B} \\
& +\gamma_{6} I_{t}+\gamma_{7} I_{t} * D_{P B B}+\gamma_{8} \theta_{i}+\gamma_{9} \theta_{i} * D_{P B B}+\gamma_{10} N U M_{t, i}+\gamma_{11} N U M_{t, i} * D_{P B B}+\varepsilon_{t}
\end{aligned}
$$

where:

$$
\begin{array}{ll}
D_{P B B} & =\begin{array}{l}
\text { a binary variable taking a value of } 1 \text { if the time period } t \text { is in a post- } \\
\text { Bubble-Bust year and } 0 \text { otherwise; }
\end{array} \\
D_{y} & =\text { a binary variable taking a value of } 1 \text { if the year equals } y \text { and } 0 \text { otherwise; }
\end{array}
$$

Because we anticipate that our variables of interest may behave differently during the "Bubble-Bust" period than in the "post-Bubble-Bust" period, we include an indicator variable $\left(D_{P B B}\right)$ to control for these differences. We define the "Bubble-Bust" period as the time prior to March 2001, as this includes the "Bubble" period and allows one year past the Nasdaq stock

\footnotetext{
${ }^{14}$ In addition, other ERC studies indicate that this relation may not manifest. For example, although Collins and Kothari (1989) find that the strength of the return-earnings relation varies with firm size, they show that the relation loses significance after other controls for differences in the information environment are considered.
} 
market peak for the "Bust" part of the cycle. ${ }^{15}$ Following Collins and Kothari (1989), we also include an indicator variable $\left(D_{y}\right)$ to control for time-series effects not considered by the other variables (particularly $D_{P B B}$ ).

The effect of the Bubble on our information content metric (AIC) is unclear. The fact that traditional valuation measures (presumably including accounting earnings) became less relevant to the market during the bubble suggests that traditional ERCs might well have experienced a decline in magnitude. Conversely, it seems possible that market participants' ability to anticipate how the stock market was likely to react to an earnings announcement and the magnitude of such a reaction declined substantively during this period as well. The increased uncertainty of exactly what metrics the market was using to value equities might lead the option's market to build in additional volatility surrounding earnings releases. Thus, it is unclear whether we would anticipate a heightened or a dampened AIC during the early years of our sample period.

The remaining variables in Equation 3 represent our cross-sectional and inter-temporal variables of interest. We gather these additional cross-sectional and time-series data required to estimate Equation 3 from Compustat and CRSP then merge this dataset with the AIC sample. ${ }^{16}$ As shown in Panel C of Table 1, this process provides a "CS sample" of 30,641 options on 2,757 unique firms. We now have 14,907 unique firm-quarters of data, averaging approximately 1,355 per year during our 11-year sample period. Panel B of Figure 2 confirms that the previously anticipated correlation between STDEV and SURPRISE holds in this subset of the AIC sample.

Finally, just as we foresee the richness of firms' information environments having an effect on the option market's anticipation of the informativeness of earnings, we also expect

\footnotetext{
${ }^{15}$ In the next section, we provide evidence that our variables of interest exhibit differences across the sub-periods.

${ }^{16}$ Please refer to the Appendix for a complete list of the variables we use in this analysis.
} 
ownership structure might influence the extent to which the option market anticipates earningsinduced trade. Extant research demonstrates that firms with higher levels of institutional ownership experience more trading volume and greater return volatility surrounding earnings releases (Potter, 1992; Kim, Krinsky, and Lee, 1997; and Lang and McNichols, 2007). Following this literature, we hypothesize that this increased level of trading activity by institutional investors results in an increase in the option market's allowance for the earningsinduced volatility, after controlling for other factors found to influence the return-earnings relation. Furthermore, as noted in Bushee and Noe (2000) and Bushee (2001), institutions differ with regard to their willingness (and ability) to trade in the short run. Because transient investors have the most intensive portfolio turnover and are the most likely to trade on earnings news, we expect that the option market anticipates an increased stock-price sensitivity to the earnings release for firms that are expected (based on ownership structure) to experience more intense trading. Thus, we hypothesize that ownership by transient investors has the most extreme effect on AICs. ${ }^{17}$

To explore this notion, we next test whether the AIC is sensitive to both levels of and changes in the firm's ownership structure. Using institutional ownership data from Thompson Reuters, we re-estimate Equation 3 including a measure of the fraction of the firm held by institutional owners $(\% \mathrm{OWN})$ and predict a positive coefficient. Because we expect this association to be particularly strong for institutions with a demonstrated willingness (or ability) to trade intensely at earnings releases, additional estimations investigate the differential impact

\footnotetext{
${ }^{17}$ Jiambalvo, Rajgopal, and Venkatachalam (2002) examine the relation between investor sophistication (as measured by institutional ownership) and the extent to which current stock prices reflect future earnings. They find that prices lead earnings to a greater extent as institutional ownership increases, which suggests a dampened market response on the earnings announcement date. In contrast, our analysis focuses on the anticipated sensitivity of the market's response to earnings information (both current and future period data) and the anticipated influence of intense trading by institutional investors - while controlling for the richness of firms' information environments and earnings persistence (as well as other previously-documented determinants of the elasticity of the market's response to earnings news). Further, our changes design allows us to speak to the impact that increases/decreases in sophisticated following has on the elasticity of the market's anticipated response.
} 
of transient institutional ownership (\%TRAN) after controlling for the other types of institutional ownership based on the classification coding described in Bushee and Noe (2000) and Bushee (2001). Then, to further isolate the impact of the presence of sophisticated investors known to trade actively based on earnings information, we exploit the frequent measurability of the AIC in order to study the influence of firm- and quarter-specific changes in ownership structure. ${ }^{18}$

\section{Analyses and results}

\section{Univariate statistics}

Panel A of Table 2 reports the results of a univariate analysis of AICs and the other variables of interest for the AIC (larger) sample. We document considerable variability in the firm- and quarter-specific measure of the option market's allowance for earnings-induced volatility. The standard deviation of the AIC is quite large relative to its mean. Using the definition of the AIC we conclude that the average option price is $\$ 5.91$. By construction, the AIC is positively correlated with IVOL and negatively correlated with STDEV.

In Panel B of Table 2, we report similar analyses of the smaller sample that has the requisite cross-sectional data. We first note that requiring CRSP and Compustat data significantly reduces the number of extreme AICs but has little effect on the median and that the mean earnings surprise, the mean implied volatility, and mean standard deviation of analyst forecasts are relatively unchanged in the smaller sample. Not surprisingly, however, requiring cross-sectional data results in a larger mean number of analysts following the firm. The average $\beta$ is close to one and the average firm has a market value that is about four and one-half times its book value. Recall, $\theta$ is one minus the estimated first-order moving average coefficient in a

\footnotetext{
${ }^{18}$ Because the ERC is an average effect across time/firms, studying quarterly changes presents a challenge. Accordingly, although an important and vast literature studies the relation between returns and earnings, limited evidence exists to address changes in (as opposed to levels of) the market's sensitivity to earnings information (see Skinner, 1990; Moreland, 1995; Hackenbrack and Hogan, 2002).
} 
MA(1) time series model. Following Collins and Kothari (1989, footnote 23), we subtract $\theta$ from one in order to ensure that the persistence parameter is positive. Using the mean AIC and STDEV, we impute a mean option price of $\$ 3.59$. The correlation matrix again reports that the AIC is negatively associated with STDEV and positively associated with IVOL by construction. In contrast to the findings of Atiase (1985), AIC is positively associated with NUM. Consistent with the literature summarized in Kothari (2001), earnings persistence is positively associated with AIC and the market-to-book ratio is positively associated with the AIC. Inconsistent with theory, the firm's systematic risk and risk-free interest rates are positively correlated with AIC. Finally, it is important to note that even at a univariate level, we observe the hypothesized positive correlation between the AIC and institutional ownership.

\section{Correlation between the AIC and the ex post stock market sensitivity to earnings surprise}

In our next set of tests, we explore the extent to option traders rationally anticipate the sensitivity of the stock market to earnings news by examining the correlation between our $e x$ ante information content metric and ex post measures of stock market behavior. As described in the previous section, our univariate comparisons are limited to observing the correlation between the firm- and quarter-specific AIC and (1) a firm-specific ERC that we obtain from estimating the slope coefficient from a simple ordinary least squares regression of earnings surprises normalized by stock price on announcement-day stock returns using the prior 20 quarters of data (following Teets and Wasley, 1996) and (2) the announcement day stock price response per unit of earnings surprise (RESPONSE). As shown in Panel A of Table 3, we observe that the correlation between the firm- and quarter-specific AIC and a firm-specific ERC is about 0.15 (statistically significant at the 0.001 level). We suspect the pooled nature of the ERC regressions introduces substantial measurement error because it assumes that a firm's earnings-return 
relation remains constant for the previous 20 quarters. Consistent with this claim, we find the correlation climbs to over 31\% when we average both AICs and ERCs within industries using either DNUM or the Fama-French Industries and in excess of 53\% when using SIC codes. ${ }^{19}$

In Panel B of Table 3, we examine the correlation between the AIC and a firm- and quarter-specific measure of the announcement-day stock price response per unit of earnings surprise (relative to the mean I/B/E/S forecast), RESPONSE. The variable RESPONSE is quite noisy; nearly $45 \%$ of the individual firm-quarter ratios are negative. As a negative RESPONSE is not economically logical (a positive earnings surprise is viewed as bad news by the market or a negative surprise as good news), we do not simply report the AIC-RESPONSE correlation (it is quite low). One modification is to focus on only the positive firm-quarter RESPONSE ratios and, therefore, make economic sense. In that case, the AIC-RESPONSE correlation is a statistically significant (at the 0.0001 confidence level) 0.47 for the large sample and .42 for the smaller sample. (Interestingly, the correlation between the AIC and the negative RESPONSE measures is of the same magnitude as the correlation with the positive RESPONSEs, only negative.) Alternatively, we can focus our attention on the relation between the AIC and the sensitivity of stock price to earnings surprise by taking the absolute value of RESPONSE before computing the correlation between it and AIC. In that case, the correlation is a statistically significant (again at the 0.0001 level) $47 \%$ for the AIC sample and $41 \%$ for the CS sample. This suggests that large AICs are correlated with extreme stock price movements per unit of earnings surprise, which is consistent with the claim that option market traders are, on average, able to anticipate the sensitivity of the ex post stock prices to earnings news.

\footnotetext{
${ }^{19}$ In unreported sensitivity analyses, we use option data farther from the earnings report date, restrict the moneyness of the options to be between 0.99 and 1.01, employ Dow Jones to determine the to-the-minute time of a subset of the earnings announcements to better classify the earnings date and use the I/B/E/S detail file to eliminate "stale" forecasts for a subset of the sample. None of these modifications substantially affect the observed AIC-ERC relation.
} 


\section{Nonlinearity of AICs}

Prior research documents that traditional ERCs are not linear in earnings surprise. Specifically, Freeman and Tse (1992) document an s-shaped relation between stock price change and earnings surprise. That is, the marginal stock price reaction to greater absolute surprises decreases as the surprise increases. We illustrate that this nonlinearity between option price (our numerator) and our earnings uncertainty proxy, the standard deviation of analysts' earnings forecasts (our denominator), holds in our sample in Figure 3. Panel A (B) of Figure 3 plots the data using the AIC (CS) sample. To produce the figures, we normalize STDEV and OPTPRC by the underlying stock's price the day prior to the earnings announcement and form normalized STDEV deciles. Consistent with Freeman and Tse (1992), the scatter plot suggests that the AIC:STDEV relation is nonlinear. That is, the AIC increases at a decreasing rate as our earnings surprise proxy (i.e., STDEV) increases.

\section{The importance of the Internet Bubble}

Before reporting the results of our estimation of regression Equation 2, we pause to consider the influence of the Internet "Bubble" period. To analyze the effect of the Bubble on our data, we report tests of the difference in means and medians for our variables of interest across the Bubble-Bust period and the post-Bubble-Bust period in Table 4. Using the larger sample of observations for which we have an AIC, we note that the mean (median) AIC in the post-Bubble-Bust period is about two-thirds (three-fourths) of the Bubble-Bust level. These differences are due to a 10-point drop in IVOL that is significant at beyond the 0.01 level. This implies that option traders anticipated a heightened volatility of stock price movements surrounding earnings releases during the Bubble. Likewise, the means and medians of SURPRISE, STDEV, NUM, and IVOL differ in the two sub-periods. The same conclusions 
hold when we examine the sample requiring the cross-sectional variables. In addition, each of the cross-sectional variables of interest ( $\theta, \beta, \mathrm{MB}$, and I - median only for MB) differ in the two sub-periods. Taken collectively, the results presented in Panels A and B of Table 4 signal the need to control for the influence of the Bubble-Bust period in our multiple regressions.

\section{Cross-sectional and inter-temporal analysis of AICs}

In Table 5, we report the results of estimating regression Equation 3. We present the results of four specifications of the regression model. The differences among the specifications stem from the inclusion of year dummy variables and the sample period employed.

Specifications (1) and (3) include year binary variables, while specifications (2) and (4) do not. The first two specifications use all years of data. The final two specifications use only 2002 through 2006 (the post-Bubble-Bust period) data.

The AIC of a firm with a high potential earnings growth rate (i.e., high $\mathrm{MB}$ ) is hypothesized to be greater than that for a firm with a low rate. Our results support this hypothesis. The Bubble-Bust period regression coefficient for MB $\left(\gamma_{2}\right)$ is significantly greater than zero. This effect is dampened in the post-Bubble-Bust period (i.e., $\gamma_{3}$ is negative), but the combined coefficient (i.e., $\gamma_{2}+\gamma_{3}$ ) applicable to the post-period is reliably positive. Likewise, option traders for a firm with large earnings persistence (i.e., a large $\theta$ ), should expect large changes in share price for a given earnings surprise. That is, we hypothesize that $\gamma_{8}$ is positive. This is not what we find in the Bubble-Bust period. Yet, the post-period coefficient $\left(\gamma_{9}\right)$ is positive and of sufficient size to swamp $\gamma_{8}$. This suggests that earnings persistence is not related to the option market's anticipation of earnings releases as expected in the Bubble-Bust period, but is related as expected in the post-period. The firm's required rate of return is hypothesized to be negatively related to the AIC. Assuming the Capital Asset Pricing Model determines the 
firm's required rate of return, the earnings-related volatility should be muted for firms with large levels of systematic risk and when riskless interest rates are high. Our evidence is consistent with the hypothesized riskless interest rate effect in the Bubble-Bust period, but only in the third specification of the model in the post-Bubble period and then only with a marginally significant p-value of 0.0567 for a two-tailed test. The evidence of the effect of the firm's systematic risk levels is not consistent with theory in the Bubble-Bust period. Our estimate of $\gamma_{4}$ is significantly positive (the unexpected sign). There is some evidence that the $\beta$-effect is consistent with theory in the post-Bubble-Bust period, as the estimate of $\gamma_{4}$ is significantly negative and the combined coefficient is significantly negative in both the second and fourth specifications (p-values of 0.0612 and 0.0069 for two-tailed tests). We note that Collins and Kothari (1989) do not consistently detect a significant effect for $\beta$.

Because firms' information environments affect the market's sensitivity to earnings information, perhaps via a "preemption" effect (Atiase, 1985), the inclusion of NUM offers the opportunity to explore the role that the increased availability of predisclosure information plays in the option market's setting. As shown in Table 4, we find the coefficient on NUM is significantly positive in both periods, which runs counter to the dampened volatility effect observed by Atiase (1985). Thus, in our sample of actively followed firms, the option market allows for a more significant earnings-related price response as the information environment becomes more robust. ${ }^{20}$

\section{The AIC's sensitivity to firms' institutional ownership}

We examine the relation between AIC and institutional ownership in Table 6 after controlling for the economic variables influencing the return-earnings relation and the richness of

\footnotetext{
${ }^{20}$ All conclusions are unchanged if we add IVOL the day prior to the EA_DATE as an explanatory variable.
} 
the firms information environment. In Panel A, we report the results of re-estimating Equation 3 after including the fraction of the firm held by institutional investors as recorded by Thompson Reuters $(\% \mathrm{OWN})$. The first two specifications represent an analysis of the cross-sectional association between levels of \%OWN and AIC; we include year fixed effects in model (1), but not in model (2). The previous documented cross-sectional and inter-temporal results are robust to the inclusion of $\% \mathrm{OWN}$ in the regression equation. In addition, we observe that the coefficient associated with institutional ownership is significantly positive for both sub-periods. This suggests that the option market builds in an increased stock-price sensitivity to the upcoming earnings announcement for those firms that are likely to be subjected to more intense institutional trading. The third specification in Panel A presents a regression of first differences of variables that change from quarter to quarter (i.e., $\mathrm{AIC}, \mathrm{MB}$, I, NUM, and \%OWN). ${ }^{21}$ Changes in AICs are positively associated with changes in the market-to-book ratio, the level of the firm's beta in the Bubble-Bust period, changes in the riskless interest rate, and changes in the number of analysts during the Bubble-Bust period and negatively related to the level of beta in the post-Bubble-Bust period. Of more interest here, changes in $\% \mathrm{OWN}$ are positively correlated with changes in the AIC. Thus, regardless of whether we examine cross-sectional levels of the AIC or changes in the AIC, we find that larger levels of institutional ownership are associated with greater anticipated volatility. This is consistent with the claim that the more intense trading activity of institutional traders is reflected in option prices surrounding earnings announcements.

In Panel B of Table 6, we report the results of the marginal effect of transient ownership on the AIC. To categorize our institutional owners as transient, dedicated, or quasi-indexers, we use data supplied to us by Brian Bushee. To update his sample period to ours, we assume that investor types remain the same over the time period from the end of his sample period (i.e.,

\footnotetext{
${ }^{21}$ The firm's $\beta$ is assessed annually and the firm's persistence parameter is estimated over the entire eleven-year sample period.
} 
2004) to the end of ours (i.e., 2006). To assess the marginal impact of transient investors, we break \%OWN into three variables; \%TRAN that represents the fraction of the firm owned by transient investors, \%DED that equals the fraction of the firm held by dedicated investors, and $\%$ QIX that is the fraction of the firm held by quasi-indexers. As described in Bushee and Noe (2000) and Bushee (2001), both \%DED and \%QIX include institutions that trade less frequently.

In Panel B of Table 6, we report the results of two levels regressions (one with year effects and one without) and one changes regression. The statistically significant effects noted in Panel A for MB, BETA, I, THETA and NUM (with the exception of the NUM-effect in the changes regression) are maintained when dividing institutional ownership into its component parts. In the Bubble-Bust period, the \%TRAN coefficient estimate is significantly positive and the $\%$ QIX coefficient is significantly negative. In the post-Bubble-Bust period, the coefficient estimate for the transient owners is significantly positive. Thus, more transient institutional ownership is associated with an increased anticipation of stock-price volatility. The size of the regression coefficient on the \%TRAN is significantly greater (results not reported, but at the 0.02 level or beyond) than the coefficients on the other two types of investors in either sub-period. Thus, highlighting the importance of Bushee (2001)'s classifications, we find that transient investors drive the positive association between institutional ownership and anticipated volatility. Tangentially, it is interesting to note that the size of the coefficient estimate for \%TRAN significantly decreases in the post-Bubble-Bust period. Not surprisingly, during that particularly volatile period, transient investors appear to have had a substantial impact.

\section{Summary of findings}

This paper draws on and contributes to research documenting the informational value of accounting earnings as well as literature studying the option market's role in the price discovery 
process in order to examine how investors' anticipation of earnings-induced stock price volatility affects trading behavior in the option market. In so doing, it offers researchers an ex ante, option-market-based measure of the informativeness of firms' earnings announcements that varies cross-sectionally and inter-temporally depending upon traders' anticipation of the strength of the return-earnings relation, the firm's information environment, and investors' willingness/ability to trade aggressively based on earnings information. In addition to documenting that option prices are sensitive to the firm and economic variables the extant earnings-information-content literature documents affect contemporaneous stock price responses to earnings innovations, our results suggest that option traders anticipate a larger potential stockprice response to earnings releases when there is more pre-announcement private information production/attention and when the firm's ownership is more inclined to trade.

The latter two results illustrate that our measure of information content (the AIC) differs from extant metrics. Atiase (1985), Collins, Kothari, and Rayburn (1987), and Collins and Kothari (1992) support the proposition that larger firms' reporting systems supply investors with data allowing stock prices to anticipate information in earnings releases and dampen the reaction to earnings news. Yet, for a sample of widely followed firms, we find that option markets buildin a greater earnings-related stock price reaction per unit of earnings uncertainty for firms with more pre-announcement information production (a larger analyst following) than when lesser amounts of pre-announcement information are present. Perhaps this is due to a belief that, should many analysts be wrong, the stock price reaction will be exaggerated relative to situations when only a few analysts are wrong. Perhaps it is because more analysts means more brokerage firms inducing more trade. Likewise, finding that the AIC is larger, on average, during the Internet Bubble than afterwards suggests that our metric responds to more than just the valuation 
relevance of current-period earnings, as accounting earnings (a traditional valuation variable)

have been shown to be less relevant during the Bubble period. Finally, we find direct evidence that the anticipated stock price reaction to an earnings release is greater if there is a higher fractional ownership of sophisticated investors willing and able to trade on information contained in earnings releases.

\section{Conclusions and future work}

We develop an ex ante measure of the information content of earnings announcements that allows us to estimate the stock market's response to news in upcoming earnings releases. Our measure, the AIC, exploits a powerful setting in the option market in order to separate the magnitude of the stock market's reaction to earnings information from earnings uncertainty. Our results suggest that option traders rationally anticipate the sensitivity of stock prices to earnings information and they do so in a way that recognizes cross-sectional and time-series differences in the strength of the link between returns and earnings. In particular, we find the AIC positively correlates with the magnitude of the ex post stock market sensitivity to unexpected earnings. In further tests, we document that the AIC increases with earnings persistence, firm growth prospects, the richness of firms' information environments and the presence of sophisticated ownership structures and decreases with anticipated discount rates. This paper sheds light on whether and how information content manifests in the option market and, in so doing, it introduces several opportunities for future study.

As with all empirical research, one must be cautious about interpreting results and extrapolating our conclusions to firms not included in our sample. The data requirements for computing AIC are somewhat restrictive, which biases our sample toward larger firms with sufficient trading interest and stock price volatility to attract the attention of option exchanges 
and financial analysts. Thus, it would be difficult to extend our findings to small firms without analyst coverage. It is important to note, however, that the nature of $\mathrm{I} / \mathrm{B} / \mathrm{E} / \mathrm{S}$ coverage and OptionMetrics coverage often leads to the exclusion of similar firms. That is, firms for which we do not observe sufficient analyst following are frequently the same firms that are do not have traded options. Consequently, traditional measures of information content (e.g., ERCs) calculated using analyst forecast data likely suffer a similar degree of restriction due to data availability. We also must recognize that the AIC undoubtedly measures the anticipated information content of earnings with error. For example, as in any event study, the option's price might be affected by information events other than earnings that the market anticipates occurring before the option's expiration. Our focus on soon-to-expire options mitigates this concern to some degree. Further moderating this concern is the knowledge that for this information to add noise to our calculation, it must be non-earnings related, yet value-relevant, information that option traders can anticipate, but to which they cannot attach an expected sign. In addition, it is possible that option market imperfections unrelated to anticipated information events (e.g., abnormal open interest that must be closed) impose increasingly greater effects on option prices as expiration approaches.

As highlighted previously, unique features of our option-market (as opposed to stockmarket) approach to studying information content introduce many avenues for future research. For example, researchers might exploit the firm- and quarter-specificity of the AIC to investigate whether firm- and quarter-specific disclosures that speak to the quality of a firm's financial reporting (e.g., abnormal discretionary accruals, restatements of previous periods' financial statements, or disclosures of a material weakness in internal control over financial reporting under Sections 302 and 404 of the Sarbanes-Oxley Act of 2002) affect investors' anticipation of 
the strength of the return-earnings relation. Following prior literature that uses the traditional ERC as a proxy for earnings quality (Teoh and Wong 1993; Moreland 1995; Hackenbrack and Hogan 2002; Balsam, Krishnan and Yang, 2003), one might expect changes in the reliability of financial statements (as measured by the presence of high abnormal accruals, a restatement, or a material weakness disclosure) to be associated with decreases in firm- and quarter-specific AICs at the time the event occurs. Indeed, the frequent availability of the AIC affords researchers the opportunity to study the influence of any event on the magnitude of the return-earnings relation on a timely basis.

Finally, the existence of multiple options that vary across three dimensions (i.e., puts versus calls, strike prices, and expiration dates) introduces additional research opportunities beyond those attributes of the AIC that allow for more powerful event studies. For example, do accounting choices have different short-term and longer-term effects on the informativeness of earnings? Options with differing expiration dates allow research on this question. Do firms' accounting choices impart an asymmetry in the strength of the link between returns and earnings? With puts and calls available, a researcher can address such questions. Should it be of interest to assess the distribution of expected future stock prices, researchers can examine options with varying strike prices. 


\section{References}

Amin, K. and C. Lee. 1997. Option trading and earnings news dissemination. Contemporary Accounting Research 14: 153-192.

Atiase, R. 1985. Predisclosure information, firm capitalization, and security price behavior around earnings announcements. Journal of Accounting Research: 21-36.

Bagnoli, M., W. Kross, and S. Watts. 2002. The information in management's expected earnings report data: a day late, a penny short. Journal of Accounting Research: 1275-1296.

Ball, R., and P. Brown. 1968. An empirical evaluation of accounting income numbers. Journal of Accounting Research 6: 159-178.

Balsam, S., J. Krishnan, J.S. Yang. 2003. Auditor industry specialization and earnings quality. Auditing: A Journal of Practice and Theory 22(2): 71-97.

Barron, O., O. Kim, S. Lim, and D. Stevens. 1998. Using analysts' forecasts to measure properties of analysts' information environment. The Accounting Review 73: 421-433.

Beaver, B. 1968. The information content of annual earnings announcements. Journal of Accounting Research: 67-92.

Beaver, W., R. Clarke, and W. Wright. 1979. The association between unsystematic security returns and the magnitude of earnings forecast errors. Journal of Accounting Research 17: 316340.

Beaver, W., R. Lambert, and D. Morse. 1980. The information content of security prices. Journal of Accounting and Economics 2: 3-28.

Black, F., and M. Scholes. 1973. The pricing of options and corporate liabilities. Journal of Political Economy 81: 637-654.

Bushee, B. 2001. Do institutional investors prefer near-term earnings over long-run value? Contemporary Accounting Research 18: 207-246.

Bushee, B. and C. Noe. 2000. Corporate disclosure practices, institutional investors, and stock return volatility. Journal of Accounting Research: 171-202.

Chambers, A., and S. Penman. 1984. Timeliness of reporting and the stock price reaction to earnings announcements. Journal of Accounting Research 22: 21-47.

Collins, D., S. P. Kothari, and J. Rayburn. 1987. Firm size and the information content of prices with respect to earnings. Journal of Accounting and Economics 9: 111-138. 
Collins, D., and S. P. Kothari. 1989. An analysis of intertemporal and cross-sectional determinants of the earnings response coefficient. Journal of Accounting and Economics 11: 143-181.

Cremers, M., and D. Weinbaum. 2010. Deviations from put call parity and stock return predictability, Journal of Financial and Quantitative Analysis, forthcoming.

Demers, E., and B. Lev. 2001. A rude awakening: Internet shakeout in 2000. Review of Accounting Studies 6: 331-349.

Easton, P., and M. Zmijewski. 1989. Cross-sectional variation in the stock market response to accounting earnings announcements. Journal of Accounting and Economics 11: 117-141.

Freeman, R., and S. Tse. 1992. A nonlinear model of security price responses to unexpected earnings. Journal of Accounting Research 30: 185-209.

Hackenbrack, K. and C. Hogan. 2002. Market response to earnings surprises conditional on reasons for an auditor change. Contemporary Accounting Research 19: 195-223.

Hand, J. 2001. The role of book incomes, web traffic, and supply and demand in the pricing of U.S. internet stocks. European Finance Review 5: 295-317.

Imhoff, E., and G. Lobo. 1992. The effect of ex ante earnings uncertainty on earnings response coefficients. The Accounting Review 67: 427-439.

Jiambalvo, J., S. Rajgopal, and M. Venkatachalam. 2002. Institutional ownership and the extent to which stock prices reflect future earnings. Contemporary Accounting Research: 117-45.

Kim, J., I. Krinsky, and J. Lee. 1997. Institutional holdings and trading volume reactions to quarterly earnings announcements. Journal of Accounting, Auditing and Finance 12: 1-14.

Kinney, W., D. Burgstahler, and R. Martin. 2002. Earnings surprise 'materiality' as measured by stock returns. Journal of Accounting Research 40: 1297-1329.

Kormendi, R., and R. Lipe. 1987. Earnings innovations, earnings persistence, and stock returns. Journal of Business 60: 323-345.

Kothari, S.P. 2001. Capital markets research in accounting. Journal of Accounting and Economics 31: 105-231.

Kothari, S.P., and R. Sloan. 1992. Information in prices about future earnings: Implications for earnings response coefficients. Journal of Accounting and Economics 14: 143-171.

Lang, M. and M. McNichols. 1997. Institutional trading and corporate performance. Working paper. 
Manaster, S. and R. Rendleman. 1982. Option prices as predictors of equilibrium stock prices. Journal of Finance 37: 1043-1057.

May, R. G. 1971. The influence of quarterly earnings announcements on investor decisions as reflected in common stock price changes. Journal of Accounting Research 9: 119-163.

Mayhew, S., and V. Mihov. 2004. How do exchanges select stocks for option listing. Journal of Finance 59: 447-471.

Moreland, K. 1995. Criticisms of auditors and the association between earnings and returns of client firms. Auditing: A Journal of Practice and Theory 14 (Spring): 94-104.

Ni, S., J. Pan, and A. Poteshman. 2008. Volatility information trading in the option market. Journal of Finance 63: 1959-1092.

Patell, J., and M. Wolfson. 1979. Anticipated information releases reflected in call option prices. Journal of Accounting and Economics 1: 117-140.

Patell, J., and M. Wolfson. 1981. The ex ante and ex post price effects of quarterly earnings announcements reflected in option and stock prices. Journal of Accounting Research 19: 434458.

Payne, J., and W. Thomas. 2003. The implications of using stock-split adjusted I/B/E/S data in empirical research. The Accounting Review 78: 1049-1067.

Potter, G. 1992. Accounting earnings announcements, institutional investor concentration and common stock returns. Journal of Accounting Research 30: 146-155.

Rogers, J., D. Skinner, and A. Van Buskirk. 2009. Earnings guidance and market uncertainty. Journal of Accounting and Economics 48: 90-109.

Schmalensee, R., and R. Trippi. 1978. Common stock volatility expectations implied by option premia. Journal of Finance 33: 129-147.

Skinner, D. 1990. Options markets and the information content of accounting earnings releases. Journal of Accounting and Economics 13: 191-211.

Teets, W., and C. Wasley. 1996. Estimating earnings response coefficients: pooled versus firmspecific models. Journal of Accounting and Economics 21: 279-295.

Teoh, S. and T. Wong. 1993. Perceived auditor quality and the earnings response coefficient. The Accounting Review 68 (April): 346-366.

Trueman, B., F. Wong, and X Zhang. 2000. The eyeballs have it: searching for the value in Internet stocks. Journal of Accounting Research 38: 137-162. 
Trueman, B., F. Wong, and X. Zhang. 2003. Anomalous stock returns around Internet firms' earnings announcements. Journal of Accounting and Economics 34: 249-271.

Xing, Y., X. Zhang, and R. Zhao. 2009. What does individual option volatility smirk tell us about future equity returns?" forthcoming Journal of Financial and Quantitative Analysis.

Xu, B., M. Magnan, and P. Andre. 2007. The stock market valuation of R\&D information in biotech firms. Contemporary Accounting Research 24: 1291-1318. 


\begin{tabular}{|c|c|c|}
\hline \multicolumn{3}{|c|}{$\begin{array}{c}\text { APPENDIX } \\
\text { Variable definitions and data sources }\end{array}$} \\
\hline OPTPRICE & $\begin{array}{l}=\text { the average of the best, or highest, closing bid price and the best, } \\
\text { or lowest, closing ask price across all exchanges on which the option } \\
\text { trades (i.e., [BEST_BID+BEST_OFFER] } \div \text { ). }\end{array}$ & \multirow{6}{*}{ OptionMetrics } \\
\hline PRICE & $\begin{array}{l}=\text { the closing price of the security; if missing, then OptionMetrics } \\
\text { takes the average of the closing bid and ask prices. }\end{array}$ & \\
\hline STRIKE & $=$ the strike price of the option. & \\
\hline EX_DATE & $=$ the expiration date of the option. & \\
\hline IVOL & $\begin{array}{l}=\text { the calculated implied volatility of the option. (OptionMetrics does } \\
\text { not calculate this for options with non-standard settlement.) }\end{array}$ & \\
\hline MONEYNESS (M) & $\begin{array}{l}=\text { PRICE } \div \text { STRIKE for call options; STRIKE } \div \text { PRICE for put } \\
\text { options. }\end{array}$ & \\
\hline EA_DATE & $=$ the report date of earnings as reported by $\mathrm{I} / \mathrm{B} / \mathrm{E} / \mathrm{S}$. & \multirow{4}{*}{$\mathbf{I} / \mathbf{B} / \mathbf{E} / \mathbf{S}$} \\
\hline SURPRISE & $\begin{array}{l}=\text { ACTUAL - MEANEST, where ACTUAL equals the actual value } \\
\text { of EPS and the MEANEST equals the mean estimate of analysts' } \\
\text { forecasts of current quarter EPS. }\end{array}$ & \\
\hline STDEV & $=$ the standard deviation of analysts' forecasts. & \\
\hline NUMEST (NUM) & $=$ the number of estimates. & \\
\hline AIC & $=$ OPTPRICE $\div$ STDEV & $\begin{array}{c}\text { OptionMetrics } \\
\& \\
\text { I/B/E/S } \\
\end{array}$ \\
\hline $\mathbf{D}_{P B B}$ & $\begin{array}{l}=1 \text { if the observation is in the post-Bubble-Bust timeframe; } 0 \\
\text { otherwise. March of } 2001 \text { marks the start of the post-Bubble-Bust } \\
\text { timeframe in our sample period. }\end{array}$ & \multirow{6}{*}{$\begin{array}{l}\text { Compustat } \\
\& \\
\text { CRSP }\end{array}$} \\
\hline MKT_BK (MB) & $\begin{array}{l}=\text { the ratio of the market capitalization to book value of equity (i.e., } \\
\text { Compustat DATA14 times Compustat DATA61 divided by } \\
\text { Compustat DATA60). }\end{array}$ & \\
\hline $\operatorname{BETA}(\beta)$ & $\begin{array}{l}=\text { systematic risk as measured by the prior year-end BETAV from } \\
\text { CRSP. }\end{array}$ & \\
\hline INT_RATE (I) & $\begin{array}{l}=\text { the } 10 \text {-year, U.S. Treasury long-term interest rate for the end of } \\
\text { the prior month. }\end{array}$ & \\
\hline THETA $(\theta)$ & $\begin{array}{l}=\text { a measure of earnings persistence, } \theta \text { equals one minus the } \\
\text { estimated first-order moving average coefficient in a time series } \\
\text { model. }\end{array}$ & \\
\hline $\operatorname{YEAR}\left(\mathrm{D}_{\mathrm{y}}\right)$ & $\begin{array}{l}=\text { a binary variable that takes the value of } 1 \text { if the year equals } y ; 0 \\
\text { otherwise. }\end{array}$ & \\
\hline$\% \mathbf{O W N}$ & $\begin{array}{l}=\text { the shares held at the end of the quarter by institutional owners } \\
\text { divided by the shares outstanding at the end of the quarter. We code } \\
\text { the types of institutional ownership - transient (\%TRAN), dedicated } \\
(\% \text { DED), and quasi-index (\%QIX) - using classification coding } \\
\text { described in Bushee and Noe (2000) and Bushee (2001). }\end{array}$ & $\begin{array}{l}\text { Thomson } \\
\text { Reuters }\end{array}$ \\
\hline RESPONSE & $=$ the announcement day stock price response $\div$ SURPRISE. & $\begin{array}{l}\text { CRSP \& } \\
\mathbf{I} / \mathbf{B} / \mathbf{E} / \mathbf{S}\end{array}$ \\
\hline
\end{tabular}


FIGURE 1

Timeline of earnings announcement date in relation to option expiration

\section{Earnings announcement date \& option expiration}

EA_DATE ${ }_{i, j}$ falls in the 20 trading days before option expiration.

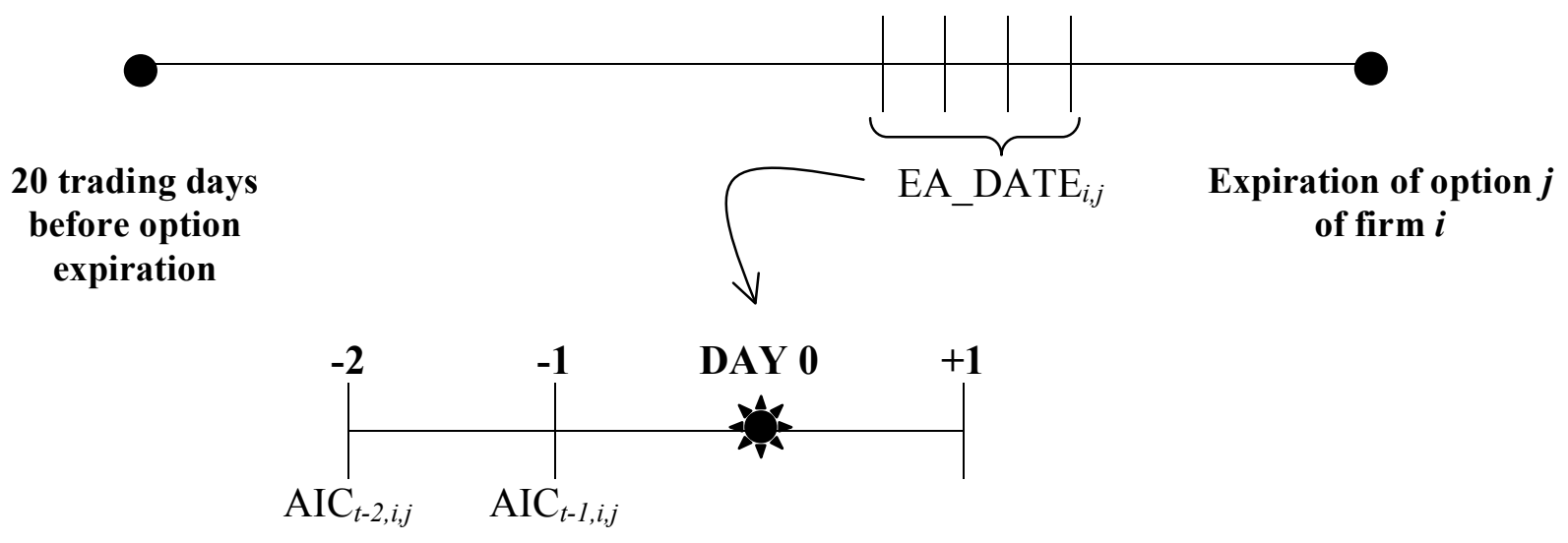

We limit our analysis to options nearing expiration by collecting data for all traded options on individual common stocks beginning four weeks (typically 20 trading days) prior to the option expiration date from OptionMetrics. We merge the OptionMetrics dataset with an I/B/E/S dataset to obtain the initial sample of firm-quarters with available option and analyst forecast data. When merging the two datasets, we require that an earnings announcement date (EA_DATE) fall within the four weeks of option data collected from OptionMetrics. Thus, all retained merged datasets contain a series of option and stock price data that covers the period of time surrounding an EA_DATE. As indicated in the lower timeline, we calculate an AIC for observations occurring one or two days before the EA_DATE. We only calculate one AIC for each unique option associated with a particular EA_DATE. Specifically, if we calculate an AIC for option $j$ on firm $i$ on day -1 , then we do not calculate an AIC on day -2. Please see the Appendix for variable definitions. 
FIGURE 2

The relation between earnings surprise and standard deviation of forecasts

\section{Panel A - AIC sample $(n=39,443)$}

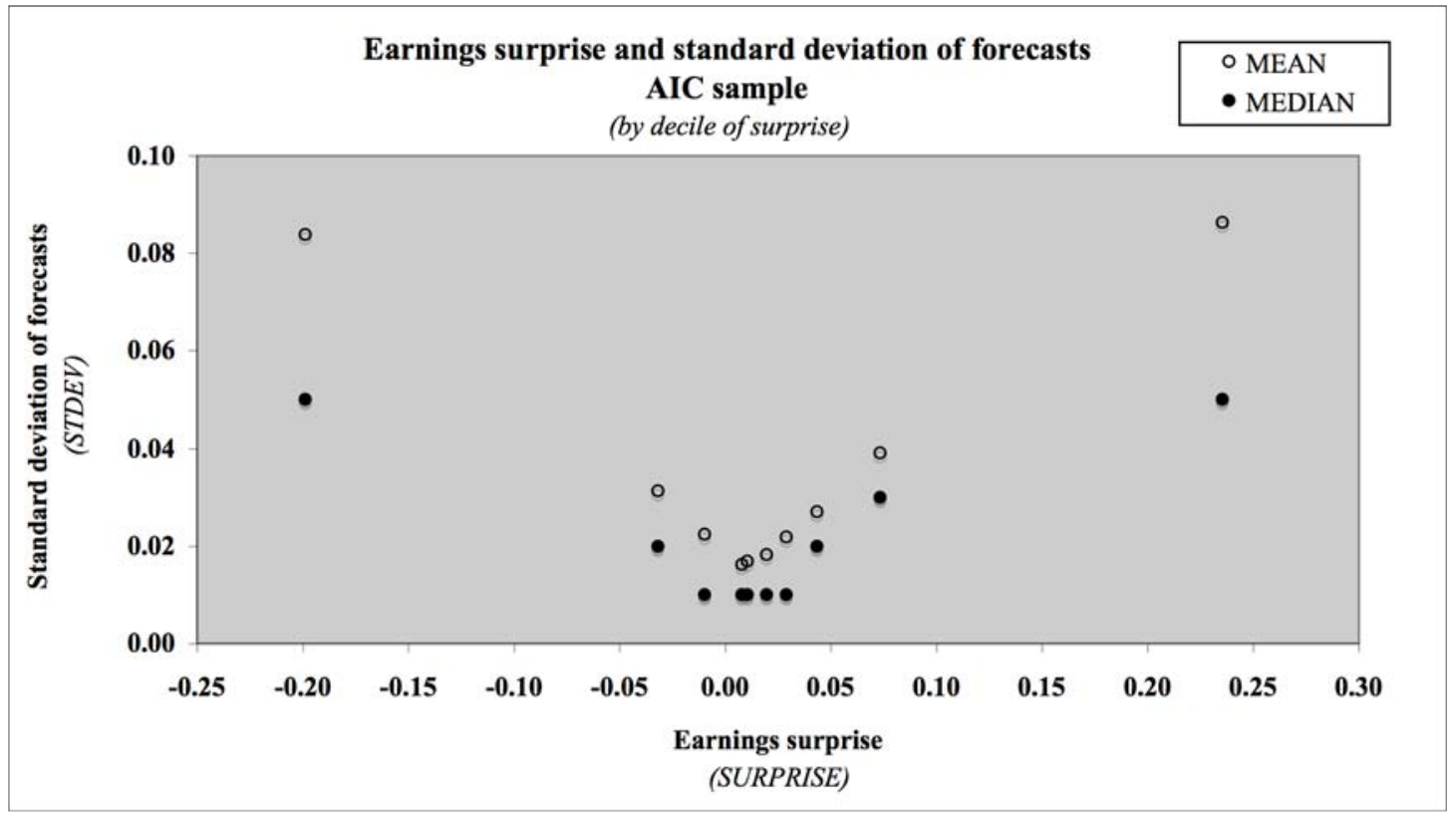

\section{Panel B - CS sample $(n=30,641)$}

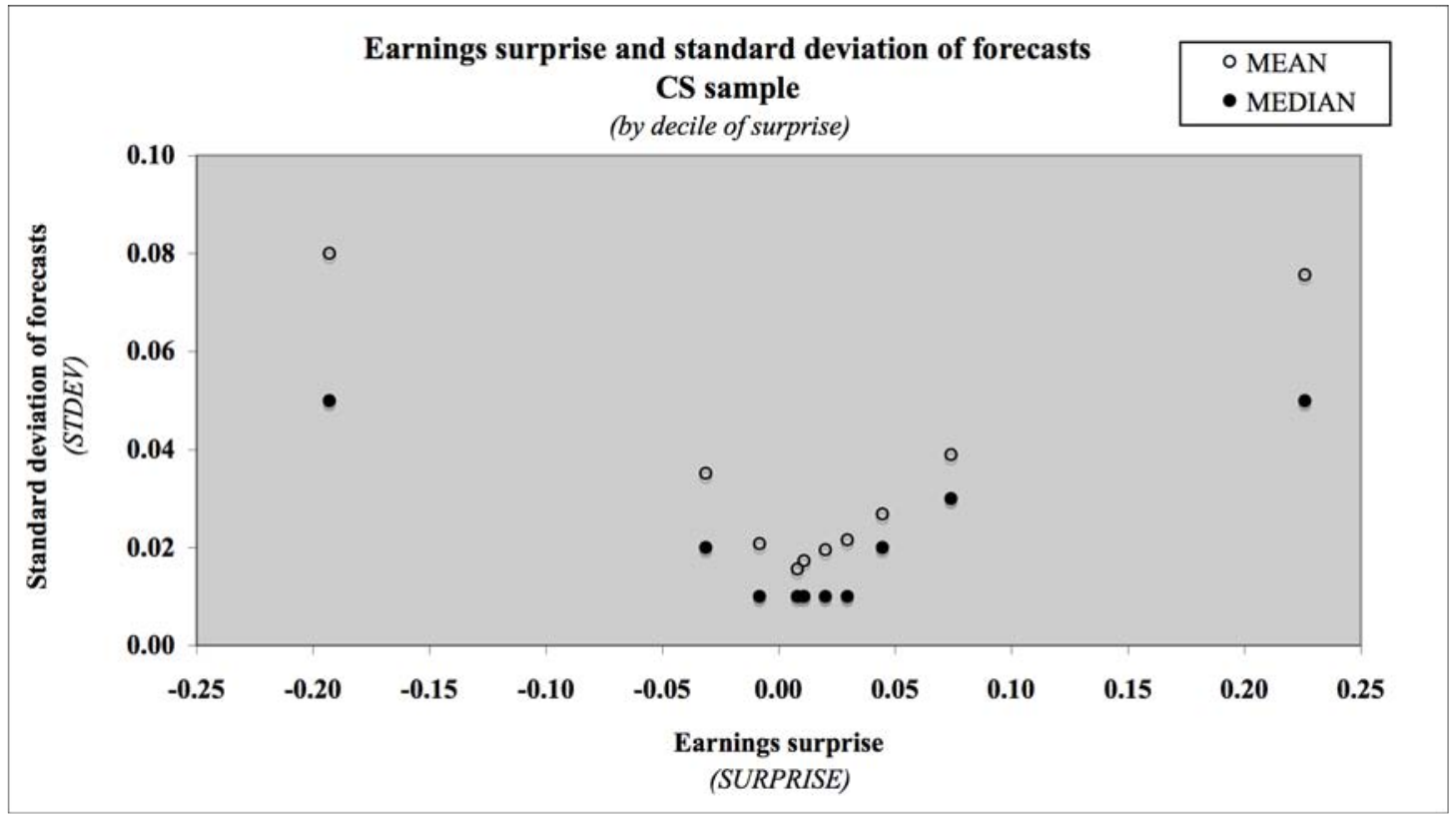

Kinney, Burgstahler and Martin (2002, Figure 3) suggest that STDEV offers a good ex ante proxy of earnings surprise. Confirming the existence of a relation in our sample, we detect a statistically significant (beyond the 0.0001 level) correlation of 0.54 between STDEV and the absolute value of SURPRISE for the sample of firms with option and analyst forecast data (the AIC sample). This figure illustrates this point by sorting our data into deciles based on SURPRISE and plotting the average SURPRISE and average STDEV for these 10 groups. Consistent with Kinney, Burgstahler and Martin (2002), we observe a linear pattern between STDEV and absolute SURPRISE. Panel B confirms that the correlation holds in the subset of firms with Compustat and CRSP data the (CS sample). Please see the Appendix for variable definitions. 
FIGURE 3

Nonlinearity

Panel A - AIC sample $(n=39,443)$

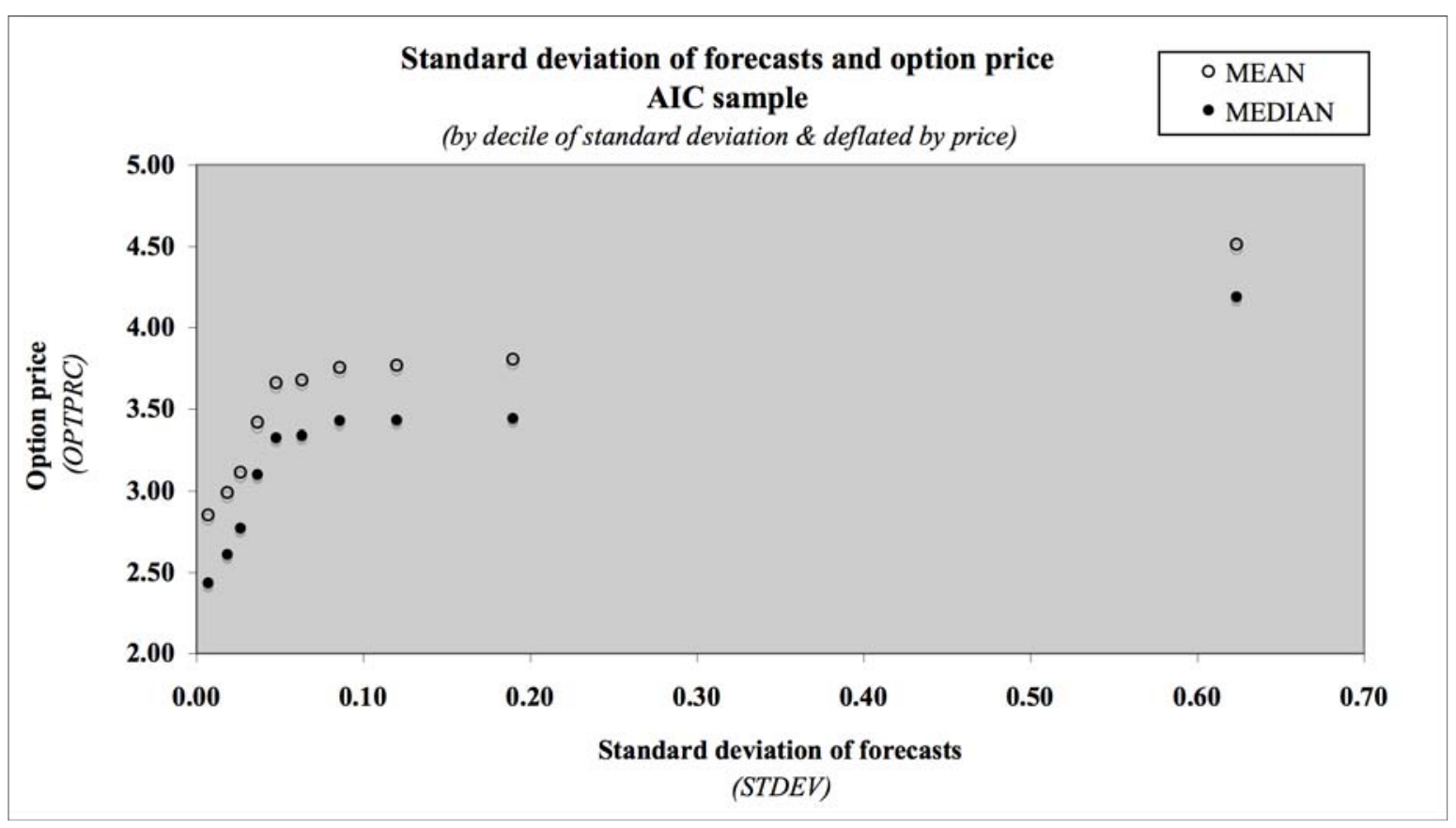

Freeman and Tse (1992) find that stock returns change rapidly as earnings surprise moves in either direction from zero, but that this sensitivity decreases for large absolute surprise. This figure illustrates that this nonlinearity holds in our sample. Panel A plots data using the sample of firms with options and analyst forecast data (the AIC sample). As in Freeman and Tse (1992), we divide the SURPRISE and the associated stock price change by the price of a share of the firm's common stock before the earnings report. We sort our observations by normalized surprise and form normalized-surprise deciles. We then compute the mean normalized price movement (return) and mean normalized surprise for each of the deciles and produce a scatter plot. For consistency, we normalize STDEV and OPTPRC by the underlying stock's price the day prior to the earnings announcement and form normalized STDEV deciles. Please see the Appendix for variable definitions. 


\section{FIGURE 3 (concluded)}

\section{Nonlinearity}

\section{Panel B - CS sample $(n=30,641)$}

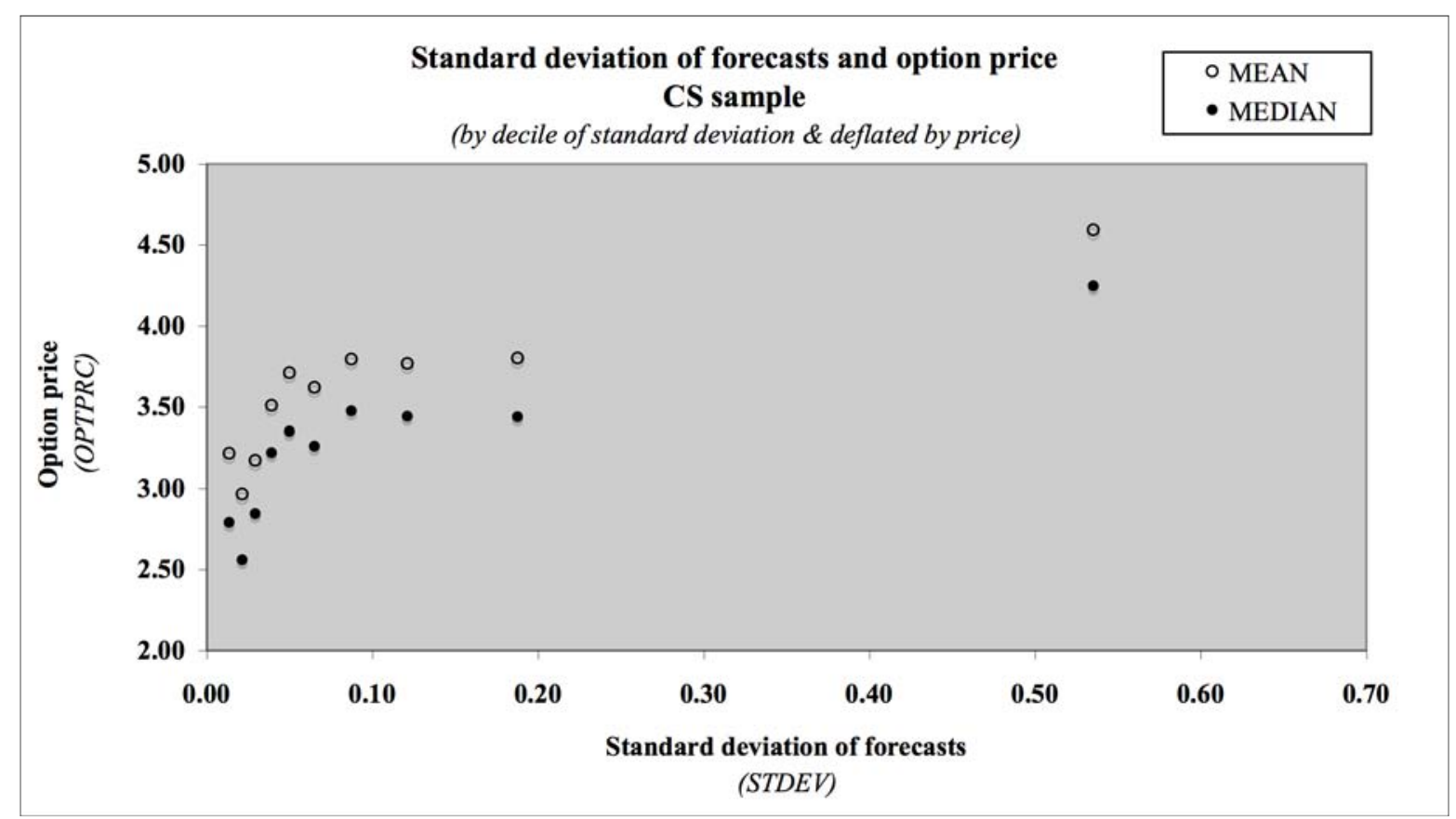

Freeman and Tse (1992) find that stock returns change rapidly as earnings surprise moves in either direction from zero, but that this sensitivity decreases for large absolute surprise. This figure illustrates that this nonlinearity holds in our sample. Panel B plots data using the sample of firms with option, analyst forecast, and Compustat and CRSP data (the CS sample). As in Freeman and Tse (1992), we divide the SURPRISE and the associated stock price change by the price of a share of the firm's common stock before the earnings report. We sort our observations by normalized surprise and form normalized-surprise deciles. We then compute the mean normalized price movement (return) and mean normalized surprise for each of the deciles and produce a scatter plot. For consistency, we normalize STDEV and OPTPRC by the underlying stock's price the day prior to the earnings announcement and form normalized STDEV deciles. Please see the Appendix for variable definitions. 


\section{TABLE 1 \\ Sample selection}

Panel A - Observations obtained from the intersection of OptionMetrics and I/B/E/S

\begin{tabular}{|c|c|c|c|c|}
\hline \multicolumn{5}{|c|}{ Intersection of OptionMetrics and $\mathbf{I} / \mathrm{B} / \mathrm{E} / \mathrm{S}$ data } \\
\hline Year & \# of obs. & $\begin{array}{l}\text { Unique firm- } \\
\text { qtrs }\end{array}$ & Unique firms & Unique options \\
\hline $\begin{array}{c}\text { Total } \\
\text { observations }\end{array}$ & $12,746,036$ & 55,936 & 4,363 & 651,811 \\
\hline 1996 & 489,569 & 4,109 & 1,433 & 31,315 \\
\hline 1997 & 952,473 & 4,972 & 1,752 & 52,403 \\
\hline 1998 & $1,113,447$ & 5,678 & 2,002 & 58,754 \\
\hline 1999 & $1,208,943$ & 6,025 & 2,084 & 67,880 \\
\hline 2000 & $1,555,374$ & 5,168 & 1,840 & 88,894 \\
\hline 2001 & $1,372,569$ & 5,089 & 1,773 & 74,259 \\
\hline 2002 & $1,259,046$ & 5,445 & 1,876 & 67,113 \\
\hline 2003 & $1,106,498$ & 5,194 & 1,801 & 57,908 \\
\hline 2004 & $1,309,563$ & 5,936 & 1,994 & 70,291 \\
\hline 2005 & $1,402,263$ & 6,343 & 2,159 & 74,469 \\
\hline 2006 & 976,291 & 4,269 & 1,525 & 51,569 \\
\hline Average per year & $1,158,731$ & 5,293 & 1,840 & 63,169 \\
\hline
\end{tabular}

In order to estimate AICs, we require option pricing data and analyst forecast data. We obtain daily historical option prices and implied volatilities along with the option characteristics (strike prices, expiration dates, and put-call indicators) for individual equity options and these options' underlying-stock prices from Ivy DB OptionMetrics. We limit our analysis to options nearing expiration by collecting data for all traded options on individual common stocks beginning four weeks (typically 20 trading days) prior to the option expiration date (EX_DATE). We obtain analyst forecast data from the summary files of I/B/E/S International, Inc. The initial sample of data retrieved from $\mathrm{I} / \mathrm{B} / \mathrm{E} / \mathrm{S}$ focuses on forecasts of current-quarter primary earnings per share for U.S. firms covered by at least two analysts. The restriction on the number of analysts allows us to have both a mean estimate (MEANEST) and a standard deviation of analysts' forecasts (STDEV). We remove observations with missing actual reported values or missing report dates of actual earnings values. We merge the OptionMetrics and $\mathrm{I} / \mathrm{B} / \mathrm{E} / \mathrm{S}$ datasets to obtain the initial sample of firm-quarters with available option and analyst forecast data. When merging the two datasets, we require that an earnings announcement date fall within the four weeks of option data collected from OptionMetrics. Thus, all retained merged datasets contain a series of option and stock price data that covers the period of time surrounding an earnings announcement date. We increase the power of our tests by restricting the dataset to observations for which we expect the impending earnings news to most significantly affect the price of the option (OPTPRC). To accomplish this, we compute the "moneyness" (M) of the option by comparing the option's strike price (STRIKE) to the underlying stock's closing price (PRICE). Specifically, we calculate M for call (put) options as PRICE (STRIKE) divided by STRIKE (PRICE). We then limit our analysis to at-the-money options by focusing on observations where $\mathrm{M}$ falls between 0.95 and 1.05. Finally, OptionMetrics does not compute implied volatility for options with non-standard settlement arrangements. Because the non-standard settlement may affect the option price in ways that add noise to our calculations, we remove observations with missing implied volatility measures. We gather the additional crosssectional and time-series data required to conduct additional analyses from Compustat and CRSP. Please see the Appendix for variable definitions. 
TABLE 1 (continued)

Sample selection

Panel B - Observations with requisite data for computation of AICs ("AIC sample")

\begin{tabular}{|c|c|c|c|c|}
\hline Year & \# of obs. & $\begin{array}{l}\text { AIC data } \\
\text { Unique firm- } \\
\text { qtrs } \\
\end{array}$ & Unique firms & Unique options \\
\hline $\begin{array}{c}\text { Total } \\
\text { observations }\end{array}$ & 39,443 & 18,214 & 3,327 & 39,443 \\
\hline 1996 & 1,846 & 1,028 & 688 & 1,846 \\
\hline 1997 & 4,464 & 1,483 & 935 & 4,464 \\
\hline 1998 & 3,084 & 1,489 & 985 & 3,084 \\
\hline 1999 & 2,671 & 1,312 & 870 & 2,671 \\
\hline 2000 & 3,481 & 1,622 & 1,007 & 3,481 \\
\hline 2001 & 3,910 & 1,592 & 968 & 3,910 \\
\hline 2002 & 3,123 & 1,565 & 965 & 3,123 \\
\hline 2003 & 3,225 & 1,619 & 943 & 3,225 \\
\hline 2004 & 3,754 & 1,820 & 1,043 & 3,754 \\
\hline 2005 & 5,164 & 2,468 & 1,342 & 5,164 \\
\hline 2006 & 4,721 & 2,216 & 1,211 & 4,721 \\
\hline Average per year & 3,586 & 1,656 & 996 & 3,586 \\
\hline
\end{tabular}

In order to estimate AICs, we require option pricing data and analyst forecast data. We obtain daily historical option prices and implied volatilities along with the option characteristics (strike prices, expiration dates, and put-call indicators) for individual equity options and these options' underlying-stock prices from Ivy DB OptionMetrics. We limit our analysis to options nearing expiration by collecting data for all traded options on individual common stocks beginning four weeks (typically 20 trading days) prior to the option expiration date (EX_DATE). We obtain analyst forecast data from the summary files of I/B/E/S International, Inc. The initial sample of data retrieved from $\mathrm{I} / \mathrm{B} / \mathrm{E} / \mathrm{S}$ focuses on forecasts of current-quarter primary earnings per share for U.S. firms covered by at least two analysts. The restriction on the number of analysts allows us to have both a mean estimate (MEANEST) and a standard deviation of analysts' forecasts (STDEV). We remove observations with missing actual reported values or missing report dates of actual earnings values. We merge the OptionMetrics and $\mathrm{I} / \mathrm{B} / \mathrm{E} / \mathrm{S}$ datasets to obtain the initial sample of firm-quarters with available option and analyst forecast data. When merging the two datasets, we require that an earnings announcement date fall within the four weeks of option data collected from OptionMetrics. Thus, all retained merged datasets contain a series of option and stock price data that covers the period of time surrounding an earnings announcement date. We increase the power of our tests by restricting the dataset to observations for which we expect the impending earnings news to most significantly affect the price of the option (OPTPRC). To accomplish this, we compute the "moneyness" (M) of the option by comparing the option's strike price (STRIKE) to the underlying stock's closing price (PRICE). Specifically, we calculate M for call (put) options as PRICE (STRIKE) divided by STRIKE (PRICE). We then limit our analysis to at-the-money options by focusing on observations where $\mathrm{M}$ falls between 0.95 and 1.05. Finally, OptionMetrics does not compute implied volatility for options with non-standard settlement arrangements. Because the non-standard settlement may affect the option price in ways that add noise to our calculations, we remove observations with missing implied volatility measures. We gather the additional crosssectional and time-series data required to conduct additional analyses from Compustat and CRSP. Please see the Appendix for variable definitions. 


\section{TABLE 1 (concluded) \\ Sample selection}

\section{Panel C - Observations with requisite data for cross-sectional regressions ("CS sample")}

\section{Intersection of AIC data and cross-sectional data}

\begin{tabular}{crrrr} 
Year & \multicolumn{2}{c}{$\begin{array}{c}\text { Unique firm- } \\
\text { qtrs }\end{array}$} & Unique firms & Unique options \\
\hline $\begin{array}{c}\text { Total } \\
\text { observations }\end{array}$ & $\mathbf{3 0 , 6 4 1}$ & $\mathbf{1 4 , 9 0 7}$ & $\mathbf{2 , 7 5 7}$ & $\mathbf{3 0 , 6 4 1}$ \\
& & & & \\
1996 & 1,528 & 860 & 573 & 1,528 \\
1997 & 2,504 & 1,208 & 768 & 2,504 \\
1998 & 2,464 & 1,193 & 805 & 2,460 \\
1999 & 2,193 & 1,076 & 721 & 2,191 \\
2000 & 2,817 & 1,314 & 812 & 2,817 \\
2001 & 2,827 & 1,382 & 846 & 2,827 \\
2002 & 2,727 & 1,367 & 843 & 2,727 \\
2003 & 1,875 & 934 & 545 & 1,875 \\
2004 & 3,288 & 1,589 & 916 & 3,288 \\
2005 & 4,497 & 2,149 & 1,157 & 4,497 \\
2006 & 3,921 & 1,835 & 1,025 & 3,921 \\
& & & & $\mathbf{8 1 9}$ \\
Average per year & $\mathbf{2 , 7 8 6}$ & $\mathbf{1 , 3 5 5}$ & & $\mathbf{2 , 7 8 5}$ \\
& & & &
\end{tabular}

In order to estimate AICs, we require option pricing data and analyst forecast data. We obtain daily historical option prices and implied volatilities along with the option characteristics (strike prices, expiration dates, and put-call indicators) for individual equity options and these options' underlying-stock prices from Ivy DB OptionMetrics. We limit our analysis to options nearing expiration by collecting data for all traded options on individual common stocks beginning four weeks (typically 20 trading days) prior to the option expiration date (EX_DATE). We obtain analyst forecast data from the summary files of I/B/E/S International, Inc. The initial sample of data retrieved from $\mathrm{I} / \mathrm{B} / \mathrm{E} / \mathrm{S}$ focuses on forecasts of current-quarter primary earnings per share for U.S. firms covered by at least two analysts. The restriction on the number of analysts allows us to have both a mean estimate (MEANEST) and a standard deviation of analysts' forecasts (STDEV). We remove observations with missing actual reported values or missing report dates of actual earnings values. We merge the OptionMetrics and $\mathrm{I} / \mathrm{B} / \mathrm{E} / \mathrm{S}$ datasets to obtain the initial sample of firm-quarters with available option and analyst forecast data. When merging the two datasets, we require that an earnings announcement date fall within the four weeks of option data collected from OptionMetrics. Thus, all retained merged datasets contain a series of option and stock price data that covers the period of time surrounding an earnings announcement date. We increase the power of our tests by restricting the dataset to observations for which we expect the impending earnings news to most significantly affect the price of the option (OPTPRC). To accomplish this, we compute the "moneyness" (M) of the option by comparing the option's strike price (STRIKE) to the underlying stock's closing price (PRICE). Specifically, we calculate M for call (put) options as PRICE (STRIKE) divided by STRIKE (PRICE). We then limit our analysis to at-the-money options by focusing on observations where $\mathrm{M}$ falls between 0.95 and 1.05. Finally, OptionMetrics does not compute implied volatility for options with non-standard settlement arrangements. Because the non-standard settlement may affect the option price in ways that add noise to our calculations, we remove observations with missing implied volatility measures. We gather the additional crosssectional and time-series data required to conduct additional analyses from Compustat and CRSP. Please see the Appendix for variable definitions. 
TABLE 2

Distributional properties and associations of AICs

Panel A - AIC sample (n=39,443): firms with option and analyst forecast data

\begin{tabular}{l|rrrrrrr} 
& \multicolumn{7}{|c}{ Descriptive statistics } \\
& Mean & Median & Std. Dev. & \multicolumn{1}{c}{$5 \%$} & $25 \%$ & $75 \%$ & $95 \%$ \\
\hline & & & & & & & \\
& 147.69 & 55.00 & 370.94 & 5.63 & 21.88 & 125.00 & 512.50 \\
AIC & 0.02 & 0.02 & 0.20 & $(0.11)$ & $(0.01)$ & 0.04 & 0.16 \\
STRPRISE & 0.04 & 0.02 & 0.08 & 0.01 & 0.01 & 0.04 & 0.12 \\
NUM & 9.76 & 8.00 & 6.50 & 2.00 & 5.00 & 13.00 & 23.00 \\
IVOL & 0.49 & 0.41 & 0.30 & 0.19 & 0.29 & 0.59 & 1.05 \\
& & & & & & &
\end{tabular}

\begin{tabular}{l|rrrr} 
& \multicolumn{4}{|c}{ Spearman correlations } \\
& SURPRISE & STDEV & NUM & \multicolumn{1}{c}{ IVOL } \\
\hline & & & & 0.1109 \\
AIC & -0.0012 & $\mathbf{- 0 . 7 0 4 2}$ & -0.0056 & $\mathbf{0 . 1 1 0 9}$ \\
SURPRISE & & $\mathbf{0 . 0 9 0 9}$ & $\mathbf{0 . 0 8 4 8}$ & $\mathbf{- 0 . 0 2 3 3}$ \\
STDEV & & & $\mathbf{0 . 0 2 4 4}$ & $\mathbf{- 0 . 0 5 4 0}$ \\
NUM & & & & $\mathbf{- 0 . 0 2 4 3}$
\end{tabular}

We present significant correlations (at the 1\% level) in bold face and italics. Please see the Appendix for variable definitions. 
TABLE 2 (concluded)

Distributional properties and associations of AICs

Panel B - CS sample (n=30,641): firms with option, analyst forecast, Compustat and CRSP data

\begin{tabular}{l|rrrrrrr} 
& \multicolumn{7}{|c}{ Descriptive statistics } \\
& Mean & Median & Std. Dev. & \multicolumn{1}{c}{$5 \%$} & \multicolumn{1}{c}{$25 \%$} & \multicolumn{1}{c}{$75 \%$} & \multicolumn{1}{c}{$95 \%$} \\
\hline AIC & 89.74 & 52.50 & 124.62 & 5.83 & 21.88 & 112.50 & 289.58 \\
SURPRISE & 0.02 & 0.02 & 0.15 & $(0.11)$ & $(0.01)$ & 0.04 & 0.16 \\
STDEV & 0.04 & 0.02 & 0.06 & 0.01 & 0.01 & 0.04 & 0.11 \\
NUM & 10.40 & 9.00 & 6.51 & 2.00 & 5.00 & 14.00 & 23.00 \\
IVOL & 0.50 & 0.42 & 0.31 & 0.19 & 0.30 & 0.61 & 1.08 \\
THETA & 1.31 & 1.31 & 0.26 & 0.88 & 1.13 & 1.49 & 1.72 \\
BETA & 1.03 & 0.97 & 0.55 & 0.22 & 0.66 & 1.33 & 2.04 \\
MB & 4.46 & 2.61 & 63.91 & 1.03 & 1.76 & 4.20 & 10.87 \\
I & 4.98 & 4.79 & 0.88 & 3.78 & 4.34 & 5.70 & 6.59 \\
\%OWN & 0.69 & 0.71 & 0.22 & 0.28 & 0.56 & 0.84 & 0.99 \\
& & & & & & &
\end{tabular}

\begin{tabular}{l|rrrrrrrrr} 
& \multicolumn{7}{|c}{ Spearman correlations } \\
& SURP & STDEV & NUM & IVOL & \multicolumn{1}{c}{$\boldsymbol{\theta}$} & \multicolumn{1}{c}{$\boldsymbol{\beta}$} & \multicolumn{1}{c}{ MB } & \multicolumn{1}{c}{ I } & \multicolumn{1}{c}{$\%$ OWN } \\
\hline AIC & 0.0225 & -0.6897 & 0.1295 & 0.1848 & 0.0220 & 0.0615 & 0.3432 & 0.0821 & 0.0824 \\
SURPRISE & & 0.0764 & 0.0498 & -0.0447 & 0.0263 & 0.0458 & 0.0307 & -0.0873 & 0.0793 \\
STDEV & & & -0.0549 & -0.1045 & 0.0208 & 0.0383 & -0.2487 & -0.0272 & -0.0009 \\
NUM & & & & -0.0849 & 0.0622 & 0.1194 & 0.1484 & -0.1153 & 0.1500 \\
IVOL & & & & & 0.0538 & 0.2003 & 0.1535 & 0.1890 & -0.0569 \\
THETA & & & & & & 0.0983 & -0.0004 & -0.0273 & -0.0127 \\
BETA & & & & & & & 0.0494 & -0.0961 & 0.1411 \\
MB & & & & & & & & 0.0549 & -0.0302 \\
I & & & & & & & & & -0.2735
\end{tabular}

We present significant correlations (at the 1\% level) in bold face and italics. Please see the Appendix for variable definitions. 


\section{TABLE 3}

Correlation between the AIC and a firm-specific ex post stock market sensitivity to earnings surprise (the Earnings Response Coefficient in Teets and Wasley, 1996)

Panel A - Spearman Correlations between AICs and firm-specific ERCs and between AICs and averages of firm-specific ERCs by firm and by industry in order to address measurement error in the firm-specific ERC.

\begin{tabular}{l|cccc} 
& Sample & $\begin{array}{c}\text { \# of } \\
\text { Obs. }\end{array}$ & $\begin{array}{c}\text { AIC:ERC } \\
\text { correlation }\end{array}$ & $\begin{array}{c}\text { Confidence } \\
\text { level }\end{array}$ \\
\hline Without averaging & AIC & 33,111 & $\mathbf{0 . 1 5 1 2}$ & $<.0001$ \\
& CS & 28,078 & $\mathbf{0 . 1 5 0 1}$ & $<.0001$ \\
Averaging variable: & & & & \\
CUSIP & & & & \\
Fama-French & AIC & 2,860 & $\mathbf{0 . 1 8 2 4}$ & $<.0001$ \\
DNUM & CS & 2,495 & $\mathbf{0 . 1 8 1 5}$ & $<.0001$ \\
AIC & 49 & $\mathbf{0 . 3 1 9 4}$ & $\mathbf{0 . 0 2 5 3}$ \\
SIC & CS & 49 & $\mathbf{0 . 3 4 6 7}$ & $\mathbf{0 . 0 1 4 7}$ \\
& AIC & 360 & $\mathbf{0 . 3 4 2 3}$ & $<.0001$ \\
& CS & 355 & $\mathbf{0 . 3 1 0 1}$ & $<.0001$ \\
& AIC & 65 & $\mathbf{0 . 5 8 0 0}$ & $<.0001$ \\
CS & 65 & $\mathbf{0 . 5 3 5 9}$ & $<.0001$ \\
& & & &
\end{tabular}

Please see the Appendix for variable definitions. 
TABLE 3 (concluded)

Correlation between the AIC and a firm- and quarter specific ex post stock market sensitivity to earnings surprise (the percent stock price movement on the earnings announcement day divided by normalized earnings surprise)

Panel B - Partitioning based on negative RESPONSE to reduce the effect of measurement error

AIC Sample $(n=39,443)$

\begin{tabular}{l|lcrrr} 
& $\begin{array}{c}\text { Absolute } \\
\text { of } \\
\text { Obs. }\end{array}$ & $\begin{array}{c}\text { value of } \\
\text { RESPONSE }\end{array}$ & AIC & $\begin{array}{c}\text { Positive } \\
\text { RESPONSE }\end{array}$ & $\begin{array}{c}\text { Negative } \\
\text { RESPONSE }\end{array}$ \\
\hline Abs. val. of & & & & & \\
RESPONSE & 39,443 & 1 & $\mathbf{0 . 4 7 4 2 1}$ & N/A & N/A \\
AIC & 39,443 & & 1 & $\mathbf{0 . 4 6 7 7 1}$ & $\mathbf{- 0 . 4 9 9 1 1}$ \\
Positive RESPONSE & 20,816 & & & & N/A \\
Negative RESPONSE & 17,611 & & & &
\end{tabular}

CS Sample $(n=30,641)$

\begin{tabular}{|c|c|c|c|c|c|}
\hline & $\begin{array}{l}\text { \# of } \\
\text { Obs. }\end{array}$ & $\begin{array}{c}\text { Absolute } \\
\text { value of } \\
\text { RESPONSE } \\
\end{array}$ & AIC & $\begin{array}{c}\text { Positive } \\
\text { RESPONSE }\end{array}$ & $\begin{array}{c}\text { Negative } \\
\text { RESPONSE }\end{array}$ \\
\hline $\begin{array}{l}\text { Abs. val. of } \\
\text { RESPONSE }\end{array}$ & 30,641 & 1 & 0.4051 & N/A & N/A \\
\hline AIC & 30,641 & & 1 & 0.4217 & -0.40544 \\
\hline Positive RESPONSE & 16,496 & & & 1 & $\mathrm{~N} / \mathrm{A}$ \\
\hline Negative RESPONSE & 13,359 & & & & 1 \\
\hline
\end{tabular}

We present significant correlations (at the 1\% level) in bold face and italics. Please see the Appendix for variable definitions. 
TABLE 4

Distributional properties of AICs in the Bubble-Bust and post-Bubble-Bust periods

Panel A - AIC sample: firms with option and analyst forecast data

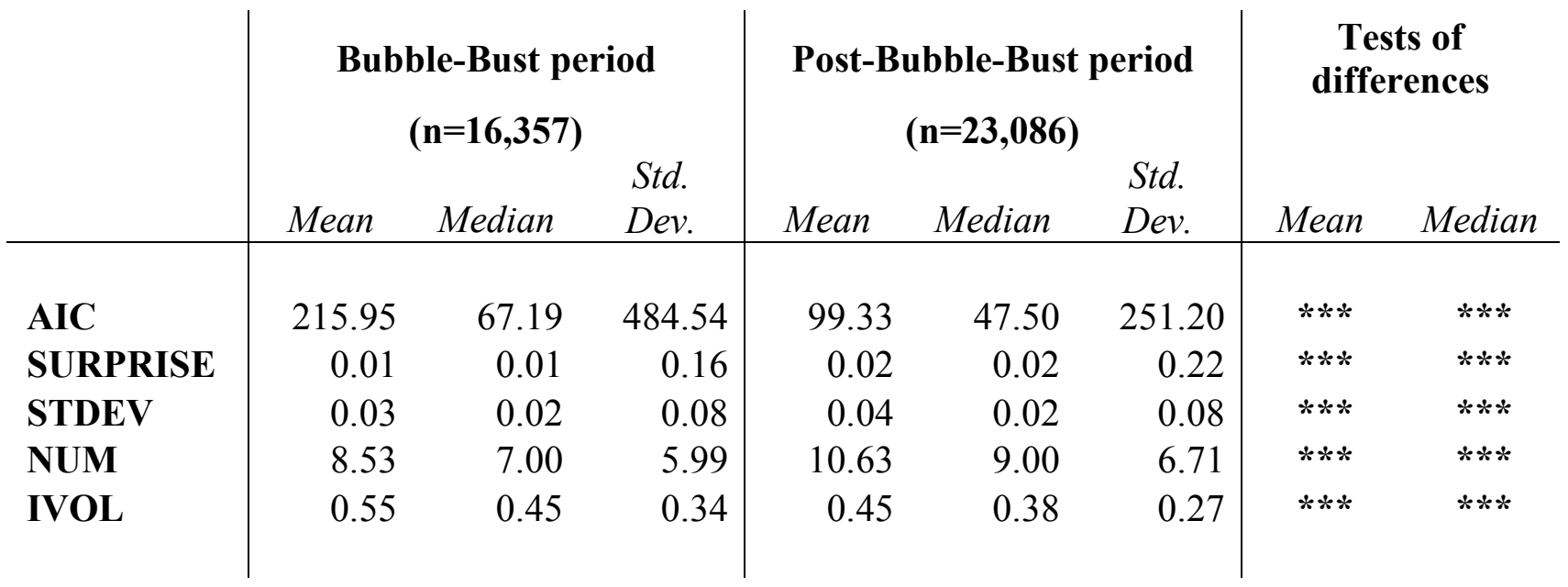

Panel B - CS sample: firms with option, analyst forecast, Compustat, and CRSP data.

\begin{tabular}{|c|c|c|c|c|c|c|c|c|}
\hline & \multicolumn{3}{|c|}{$\begin{array}{l}\text { Bubble-Bust period } \\
\qquad(\mathrm{n}=12,224)\end{array}$} & \multicolumn{3}{|c|}{$\begin{array}{l}\text { Post-Bubble-Bust period } \\
\qquad(\mathrm{n}=18,417)\end{array}$} & \multicolumn{2}{|c|}{$\begin{array}{c}\text { Tests of } \\
\text { differences }\end{array}$} \\
\hline & Mean & Median & $\begin{array}{l}\text { Std. } \\
\text { Dev. }\end{array}$ & Mean & Median & $\begin{array}{l}\text { Std. } \\
\text { Dev. }\end{array}$ & Mean & Median \\
\hline AIC & 113.51 & 60.94 & 166.99 & 73.96 & 47.50 & 81.89 & $* * *$ & $* * *$ \\
\hline SURPRISE & 0.01 & 0.01 & 0.13 & 0.02 & 0.02 & 0.16 & $* * *$ & $* * *$ \\
\hline STDEV & 0.03 & 0.02 & 0.05 & 0.04 & 0.02 & 0.06 & $* * *$ & $* * *$ \\
\hline NUM & 9.35 & 8.00 & 6.12 & 11.09 & 10.00 & 6.67 & $* * *$ & $* * *$ \\
\hline IVOL & 0.57 & 0.48 & 0.34 & 0.45 & 0.38 & 0.27 & $* * *$ & $* * *$ \\
\hline THETA & 1.29 & 1.30 & 0.26 & 1.31 & 1.31 & 0.26 & $* * *$ & $* * *$ \\
\hline BETA & 0.96 & 0.89 & 0.57 & 1.08 & 1.01 & 0.54 & $* * *$ & $* * *$ \\
\hline MB & 4.66 & 2.75 & 27.95 & 4.33 & 2.54 & 79.23 & & $* * *$ \\
\hline I & 5.83 & 5.92 & 0.60 & 4.41 & 4.35 & 0.49 & $* * *$ & $* * *$ \\
\hline
\end{tabular}

$* * *, * *, *$ denote instances where the characteristic of the post-Bubble-Bust period sample differs significantly from the BubbleBust period sample at the $1 \%, 5 \%$, and 10\% level, respectively, for two-tailed tests. March of 2001 marks the start of the postBubble-Bust timeframe in our sample period. Accordingly, the Bubble-Bust period includes observations from January of 1996 through February of 2001 and the post-Bubble-Bust period includes observations from March of 2001 through December of 2006. Please see the Appendix for variable definitions. 
TABLE 5

Cross-sectional regressions of Anticipated Information Content (AIC)

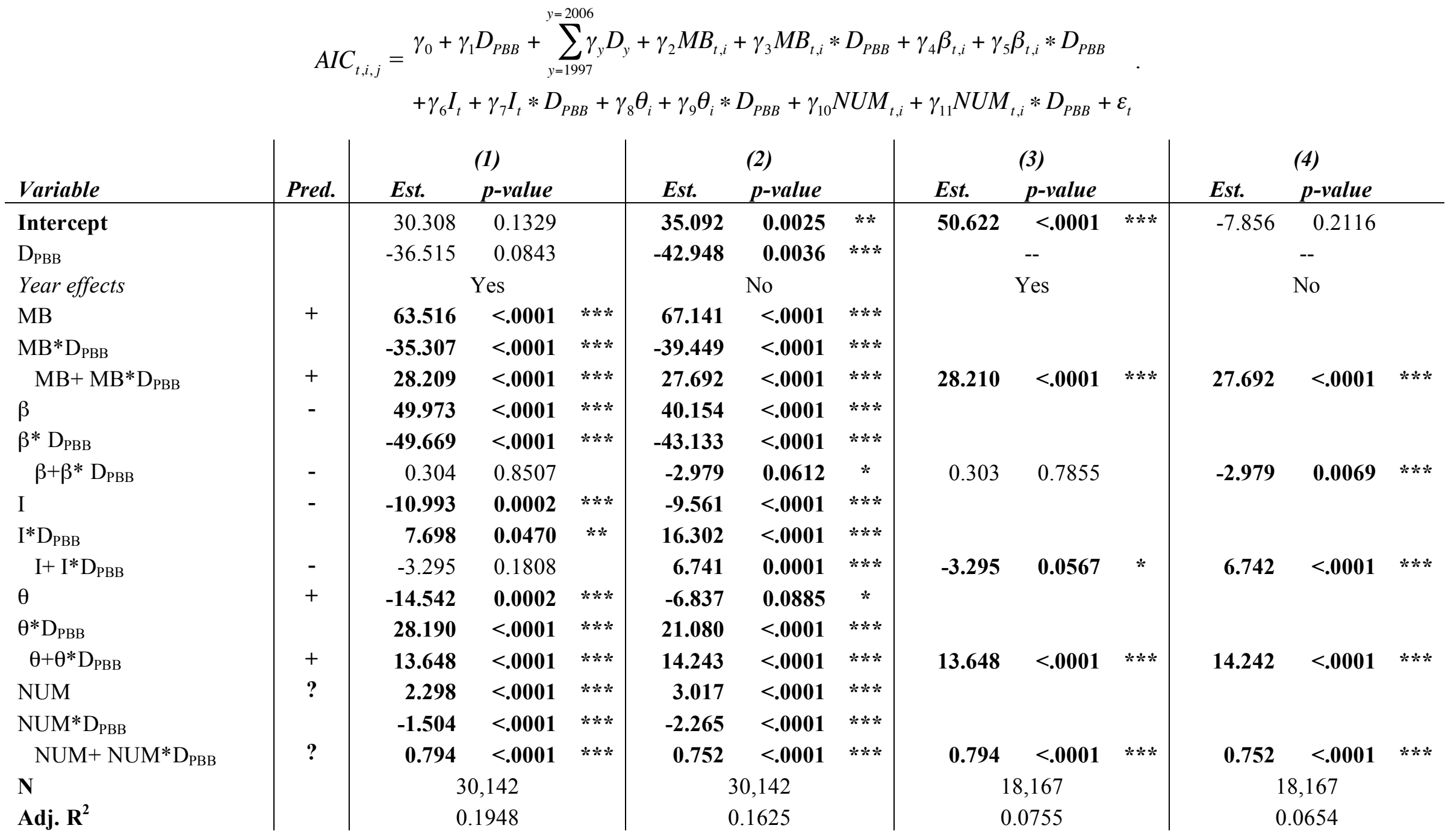

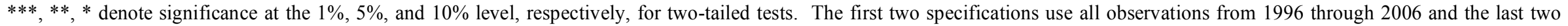
specifications use only observations from March 2001 through 2006. Please see the Appendix for variable definitions. 
TABLE 6 - Panel A

The Anticipated Information Content (AIC's) sensitivity to firms' institutional ownership

$$
\begin{aligned}
& \gamma_{0}+\gamma_{1} D_{P B B}+\sum_{y=1997}^{y=2006} \gamma_{y} D_{y}+\gamma_{2} M B_{t, i}+\gamma_{3} M B_{t, i} * D_{P B B} \\
A I C_{t, i, j}= & +\gamma_{4} \beta_{t, i}+\gamma_{5} \beta_{t, i} * D_{P B B}+\gamma_{6} I_{t}+\gamma_{7} I_{t} * D_{P B B}+\gamma_{8} \theta_{i}+\gamma_{9} \theta_{i} * D_{P B B} \\
& +\gamma_{10} N U M_{t, i}+\gamma_{11} N U M_{t, i} * D_{P B B}+\gamma_{12} \% O W N_{t, i}+\gamma_{13} \% O W N_{t, i} * D_{P B B}+\varepsilon_{t}
\end{aligned}
$$

\begin{tabular}{|c|c|c|c|c|c|c|c|c|c|c|}
\hline \multirow[b]{2}{*}{ Variable } & \multirow[b]{2}{*}{ Pred. } & \multicolumn{3}{|c|}{ (1) - Levels } & \multicolumn{3}{|c|}{$\begin{array}{c}\text { (2) }- \text { Levels } \\
p-\end{array}$} & \multicolumn{3}{|c|}{ (3) - Changes } \\
\hline & & Est. & p-value & & Est. & value & & Est. & p-value & \\
\hline Intercept & & -0.644 & 0.9748 & & 4.034 & 0.7374 & & -13.041 & 0.0468 & $* *$ \\
\hline $\mathrm{D}_{\mathrm{PBB}}$ & & -32.821 & 0.1276 & & -43.103 & 0.0050 & $* * *$ & 25.071 & 0.0007 & $* * *$ \\
\hline Year effects & & & Yes & & & No & & & Yes & \\
\hline MB & + & 65.012 & $<.0001$ & $* * *$ & 68.795 & $<.0001$ & $* * *$ & 49.687 & $<.0001$ & $* * *$ \\
\hline$M B^{*} \mathrm{D}_{\mathrm{PBB}}$ & & -36.628 & $<.0001$ & $* * *$ & -41.037 & $<.0001$ & $* * *$ & -16.350 & $<.0001$ & $* * *$ \\
\hline $\mathrm{MB}+\mathrm{MB}^{*} \mathrm{D}_{\mathrm{PBB}}$ & + & 28.384 & $<.0001$ & $* * *$ & 27.758 & $<.0001$ & $* * *$ & 33.337 & $<.0001$ & $* * *$ \\
\hline$\beta$ & - & 50.035 & $<.0001$ & $* * *$ & 40.228 & $<.0001$ & $* * *$ & 6.132 & 0.0017 & $* * *$ \\
\hline$\beta * \mathrm{D}_{\mathrm{PBB}}$ & & -51.802 & $<.0001$ & $* * *$ & -45.644 & $<.0001$ & $* * *$ & -10.166 & $<.0001$ & $* * *$ \\
\hline$\beta+\beta^{*} \mathrm{D}_{\mathrm{PBB}}$ & - & -1.767 & 0.2757 & & -5.416 & 0.0008 & $* * *$ & -4.034 & 0.0113 & $* *$ \\
\hline I & - & -10.908 & 0.0003 & $* *$ & -9.819 & $<.0001$ & $* * *$ & 12.927 & $<.0001$ & $* * *$ \\
\hline$I^{*} D_{\mathrm{PBB}}$ & & 7.398 & 0.0562 & $*$ & 17.319 & $<.0001$ & $* * *$ & -3.381 & 0.1669 & \\
\hline $\mathrm{I}+\mathrm{I}^{*} \mathrm{D}_{\mathrm{PBB}}$ & - & -3.510 & 0.1540 & & 7.500 & $<.0001$ & $* * *$ & 9.546 & $<.0001$ & $* * *$ \\
\hline$\theta$ & + & -13.087 & 0.0009 & $* * *$ & -5.220 & 0.1941 & & -2.766 & 0.4968 & \\
\hline$\theta * D_{\mathrm{PBB}}$ & & 26.439 & $<.0001$ & $* * *$ & 19.395 & 0.0002 & $* * *$ & 2.439 & 0.6345 & \\
\hline$\theta+\theta^{*} \mathrm{D}_{\mathrm{PBB}}$ & + & 13.352 & $<.0001$ & $* * *$ & 14.175 & $<.0001$ & $* * *$ & -0.327 & 0.9166 & \\
\hline NUM & $?$ & 2.001 & $<.0001$ & $* * *$ & 2.695 & $<.0001$ & $* * *$ & 1.644 & $<.0001$ & $* * *$ \\
\hline$N U M^{*} D_{\mathrm{PBB}}$ & & -1.311 & $<.0001$ & $* * *$ & -2.039 & $<.0001$ & $* * *$ & -1.514 & 0.0005 & $* * *$ \\
\hline $\mathrm{NUM}+\mathrm{NUM}^{*} \mathrm{D}_{\mathrm{PBB}}$ & $?$ & 0.697 & $<.0001$ & $* * *$ & 0.656 & $<.0001$ & $* * *$ & 0.130 & 0.6832 & \\
\hline$\% \mathrm{OWN}$ & + & 48.965 & $<.0001$ & $* * *$ & $\mathbf{5 2 . 5 0 7}$ & $<.0001$ & $* * *$ & 25.071 & 0.0007 & $* * *$ \\
\hline$\% \mathrm{OWN} * \mathrm{D}_{\mathrm{PBB}}$ & & 0.908 & 0.8891 & & -9.736 & 0.1408 & & -1.499 & 0.8908 & \\
\hline$\% \mathrm{OWN}+\% \mathrm{OWN} * \mathrm{D}_{\mathrm{PBB}}$ & + & 49.873 & $<.0001$ & $* * *$ & 42.771 & $<.0001$ & $* * *$ & 23.572 & 0.0034 & $* * *$ \\
\hline $\mathbf{N}$ & & & 29,959 & & & 9,959 & & & 27,143 & \\
\hline Adj. $\mathbf{R}^{2}$ & & & 0.2016 & & & .1687 & & & 0.0367 & \\
\hline
\end{tabular}

$* * *, * *, *$ denote significance at the $1 \%, 5 \%$, and $10 \%$ level, respectively, for two-tailed tests. In the third specification, we take first differences of all variables that can change from quarter to quarter. That includes: AIC, MB, I, NUM, IVOL, and \%OWN. Please see the Appendix for variable definitions. 
TABLE 6 - Panel B (with Bushee Classifications) The Anticipated Information Content (AIC's) sensitivity to firms' institutional ownership

\begin{tabular}{|c|c|c|c|c|c|c|c|c|c|c|}
\hline Variable & Pred. & \multicolumn{3}{|c|}{ (1) - Levels } & \multicolumn{3}{|c|}{ (2) - Levels } & \multicolumn{3}{|c|}{ (3) - Changes } \\
\hline Intercept & & -35.769 & 0.1571 & & 6.750 & 0.6640 & & -7.691 & 0.3041 & \\
\hline $\mathrm{D}_{\mathrm{PBB}}$ & & -2.834 & 0.9122 & & -24.524 & 0.2014 & & -11.402 & 0.2391 & \\
\hline Year effects & & & Yes & & & No & & & Yes & \\
\hline MB & + & 55.316 & $<.0001$ & $* * *$ & 57.436 & $<.0001$ & $* * *$ & 40.186 & $<.0001$ & $* * *$ \\
\hline$M B^{*} D_{\mathrm{PBB}}$ & & -28.106 & $<.0001$ & $* * *$ & -30.973 & $<.0001$ & $* * *$ & -1.233 & 0.7707 & \\
\hline $\mathrm{MB}+\mathrm{MB}^{*} \mathrm{D}_{\mathrm{PBB}}$ & + & 27.210 & $<.0001$ & $* * *$ & 26.463 & $<.0001$ & $* * *$ & 38.953 & $<.0001$ & $* * *$ \\
\hline$\beta$ & - & 45.386 & $<.0001$ & $* * *$ & 33.574 & $<.0001$ & $* * *$ & 4.591 & 0.0421 & $* *$ \\
\hline$\beta^{*} \mathrm{D}_{\mathrm{PBB}}$ & & -44.690 & $<.0001$ & $* * *$ & -36.045 & $<.0001$ & $* * *$ & -9.349 & 0.0022 & $* * *$ \\
\hline$\beta+\beta * D_{\mathrm{PBB}}$ & - & 0.696 & 0.7391 & & -2.471 & 0.2378 & & 4.758 & 0.0200 & $* *$ \\
\hline I & - & -2.993 & 0.4268 & & -6.534 & 0.0044 & & 22.165 & $<.0001$ & $* * *$ \\
\hline$I^{*} D_{\mathrm{PBB}}$ & & -0.096 & 0.9835 & & 10.100 & 0.0010 & $* * *$ & -12.902 & 0.0001 & $* * *$ \\
\hline $\mathrm{I}+\mathrm{I}^{*} \mathrm{D}_{\mathrm{PBB}}$ & - & -3.089 & 0.2619 & & 3.566 & 0.0805 & $*$ & 9.263 & $<.0001$ & $* * *$ \\
\hline$\theta$ & + & -13.610 & 0.0020 & $* * *$ & -6.997 & 0.1176 & & -3.389 & 0.4715 & \\
\hline$\theta^{*} \mathrm{D}_{\mathrm{PBB}}$ & & 18.726 & 0.0014 & $* * *$ & 13.942 & 0.0190 & $* *$ & 1.494 & 0.8048 & \\
\hline$\theta+\theta^{*} \mathrm{D}_{\mathrm{PBB}}$ & + & 5.116 & 0.1850 & & 6.945 & 0.0765 & $*$ & -1.895 & 0.6174 & \\
\hline NUM & $?$ & 2.955 & $<.0001$ & $* * *$ & 3.538 & $<.0001$ & $* * *$ & 1.976 & $<.0001$ & $* * *$ \\
\hline$N U M * D_{\mathrm{PBB}}$ & & -1.969 & $<.0001$ & $* * *$ & -2.683 & $<.0001$ & $* * *$ & -2.381 & $<.0001$ & $* * *$ \\
\hline $\mathrm{NUM}+\mathrm{NUM}^{*} \mathrm{D}_{\mathrm{PBB}}$ & $?$ & 0.986 & $<.0001$ & $* * *$ & 0.855 & $<.0001$ & $* * *$ & -0.405 & 0.3346 & \\
\hline$\%$ TRAN & + & 210.385 & $<.0001$ & $* * *$ & 282.953 & $<.0001$ & $* * *$ & 155.766 & $<.0001$ & $* * *$ \\
\hline$\%$ TRAN $* D_{\mathrm{PBB}}$ & & -122.747 & $<.0001$ & $* * *$ & -172.171 & $<.0001$ & $* * *$ & -109.197 & $<.0001$ & $* * *$ \\
\hline$\%$ TRAN+\%TRAN $* \mathrm{D}_{\mathrm{PBB}}$ & + & 87.638 & $<.0001$ & $* * *$ & 110.782 & $<.0001$ & $* * *$ & 46.569 & 0.0025 & $* * *$ \\
\hline$\%$ DED & + & 48.291 & $<.0001$ & $* * *$ & -4.971 & 0.6210 & & -59.608 & 0.0018 & $* * *$ \\
\hline$\% \mathrm{DED}^{*} \mathrm{D}_{\mathrm{PBB}}$ & & -49.986 & 0.0027 & $* *$ & 25.229 & 0.1243 & & 81.100 & 0.0113 & $* *$ \\
\hline$\% \mathrm{DED}+\% \mathrm{DED} * \mathrm{D}_{\mathrm{PBB}}$ & + & -1.695 & 0.8964 & & 20.258 & 0.1153 & & 21.492 & 0.4023 & \\
\hline$\%$ QIX & + & -61.315 & $<.0001$ & $* * *$ & -69.939 & $<.0001$ & $* * *$ & -18.687 & 0.2649 & \\
\hline$\% \mathrm{QIX}^{*} \mathrm{D}_{\mathrm{PBB}}$ & & 106.619 & $<.0001$ & $* * *$ & 69.209 & $<.0001$ & $* * *$ & 27.857 & 0.2347 & \\
\hline$\% \mathrm{QIX}+\% \mathrm{QIX} * \mathrm{D}_{\mathrm{PBB}}$ & + & 45.304 & $<.0001$ & $* * *$ & -0.730 & 0.9260 & & 9.170 & 0.5757 & \\
\hline $\mathbf{N}$ & & & 3,663 & & & 3,663 & & & 0,210 & \\
\hline $\operatorname{Adj} . \mathbf{R}^{2}$ & & & 2135 & & & 1857 & & & 0311 & \\
\hline
\end{tabular}

$* * *, * * *$ denote significance at the $1 \%, 5 \%$, and $10 \%$ level, respectively, for two-tailed tests. In the third specification, we take first differences of all variables that can change from quarter to quarter. That includes: AIC, MB, I, NUM, IVOL, \%TRAN, \%DED, and \%QIX. Please see the Appendix for variable definitions. 